\title{
A holistic investigation of natural gas-diesel dual fuel combustion with dual direct injection for passenger car applications
}

\author{
Paul Fasching $^{1} \cdot$ Florian Sprenger $^{1} \cdot$ Christina Granitz $^{1}$
}

Received: 10 March 2017/ Accepted: 13 June 2017/Published online: 10 July 2017

(c) The Author(s) 2017. This article is an open access publication

\begin{abstract}
This publication covers the investigation of a dual fuel combustion process for passenger car applications using natural gas and diesel as fuels. In the literature a widely studied dual fuel concept is the combination of port fuel injection of natural gas and direct injection of diesel. The challenge of this concept is a high emission of unburned hydrocarbons at low load operation as previous publications show. The proposed concept features a low pressure direct injection of natural gas in combination with direct injection of diesel to circumvent this problem. The acronym DDI—dual direct injection is introduced for this concept. It enables charge stratification of the air-natural gas mixture. This allows for a significant reduction of the unburned hydrocarbon emissions as earlier studies already demonstrated. The focus of this publication is on hardware variations which were performed on the engine test bench. Results are presented of a variation of the compression ratio and of different charge motion patterns which were studied. The results are compared with a conventional diesel and a gasoline spark ignited engine. The investiga-
\end{abstract}

Paul Fasching

fasching@ivt.tugraz.at

Florian Sprenger

sprenger@ivt.tugraz.at

Christina Granitz

granitz@ivt.tugraz.at

1 Institute of Internal Combustion Engines and Thermodynamics, Graz University of Technology, Inffeldgasse 19, 8010 Graz, Austria tions demonstrate that a $\mathrm{CO}_{2}$ reduction of $20-29 \%$ is feasible as compared to conventional engines. Finally, investigations of exhaust gas aftertreatment with a threeway catalyst are published. The aftertreatment of the remaining engine-out hydrocarbon emissions is still the key challenge due to the low exhaust gas temperature during low load operation.

Keywords Dual fuel $\cdot$ CNG $\cdot$ Diesel $\cdot$ Dual direct injection - Natural gas direct injection - Diesel pilot injection
Abbreviations
BTE Brake thermal efficiency
CNG Compressed natural gas
$\mathrm{COV}$ Coefficient of variation
DDI Dual direct injection
DF Dual fuel
DI Direct injection
DoE Design of experiments
DPI Diesel pilot injection
EGT Exhaust gas temperature
GDI Gasoline direct injection
GHG Greenhouse gas
HC Hydrocarbon
HD Heavy duty
HPDI High pressure direct injection
LPDI Low pressure direct injection
NG Natural gas
PC Passenger car
PFI Port fuel injection
ROHR Rate of heat release
SI Spark ignition
TWC Three-way catalyst 


\section{Introduction}

Compliance with increasingly stringent emission limits is a major challenge for the automotive industry. Not only pollutant emissions, but also carbon dioxide $\left(\mathrm{CO}_{2}\right)$ emissions are tightly regulated in all key markets. This is an effort to mitigate the influence of transportation on our environment as $\mathrm{CO}_{2}$ is the major greenhouse gas (GHG) and driver of global warming.

Since 2015 the $\mathrm{CO}_{2}$ emissions of new passenger cars (PC) in Europe must on average be below $130 \mathrm{~g} / \mathrm{km}$. This limit is lowered to $95 \mathrm{~g} / \mathrm{km}$ from 2020 onwards. The limit is linked to the vehicle's weight and valid for a reference weight of $1392 \mathrm{~kg}$ as Fig. 1 demonstrates [3]. The chart illustrates the portfolio of a European OEM in 2015. PCs with diesel engines fulfil the limit of $130 \mathrm{~g} / \mathrm{km}$ to a significant extent. Hybrid electric vehicles (HEV) and battery electric vehicles (BEV) are well below the limit of 2020. However, only a small share of PCs with gasoline engines achieves the 2015 limit. In order to reach the target of 2020 it is inevitable for OEMs to invest in technologies which can both be realised in the short-term and have the prospect of a high $\mathrm{CO}_{2}$ saving potential.

Alternative fuels are a promising field of research. Natural gas (NG) offers a considerable potential for reducing $\mathrm{CO}_{2}$ emissions due to its chemical structure. NG consists mainly of methane $\left(\mathrm{CH}_{4}\right)$, which has a hydrogencarbon-ratio (H-C-ratio) of 4 while common gasoline and diesel fuels only have a $\mathrm{H}-\mathrm{C}$-ratio of approximately 1.8 [7]. Assuming equal brake thermal efficiencies and complete combustion $\mathrm{CH}_{4}$ produces $25 \%$ less $\mathrm{CO}_{2}$ than gasoline or diesel fuels. No other fossil fuel facilitates such a $\mathrm{CO}_{2}$ reduction potential while maintaining the use of wellproven technologies.

NG engines in PCs are usually designed as bivalent engines and run on $\mathrm{CNG}$ and gasoline. This means they offer the possibility to switch between these two fuels, but run on one fuel at a time. In contrast, in dual fuel (DF) combustion two fuels are used simultaneously. In this work a dual fuel combustion process is investigated for PC engines using compressed natural gas (CNG) and diesel. The aim is to combine the high efficiency of a diesel engine with the $\mathrm{CO}_{2}$ savings potential of NG. In order to maximise the $\mathrm{CO}_{2}$ saving the natural gas energy fraction $x_{\mathrm{NG}}$ (as defined in Sect. 3) needs to be as large as possible as Fig. 2 illustrates.

A widely studied DF concept is the combination of port fuel injection (PFI) of NG with direct injection (DI) of diesel. In this concept a homogeneous air-NG mixture in the combustion chamber is ignited by a diesel pilot injection (DPI). The problem of this approach is in the high

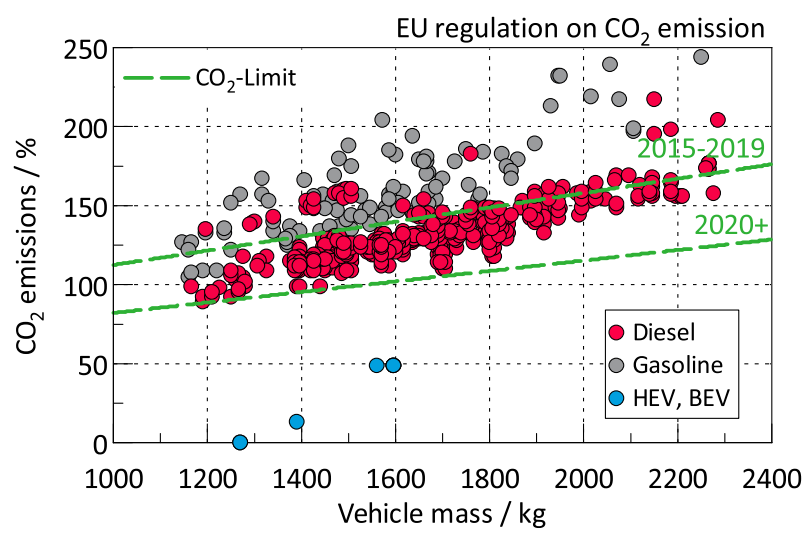

Fig. $1 \mathrm{CO}_{2}$ emission limits in Europe and the portfolio of a European OEM in 2015

unburned hydrocarbon (HC) emission at low load operation as detailed in Sect. 4. A different concept is thus proposed in this work, which features low pressure direct injection of NG. It enables charge stratification of the air-NG mixture. This allows for a significant reduction of the HC emissions as demonstrated by the authors in $[4,20,21]$. The term dual direct injection (DDI) is introduced for this concept.

DF combustion is fundamentally different from homogeneous charge compression ignition (HCCI), reactivity controlled compression ignition (RCCI) or similar concepts. In the latter, the start of combustion results only from the pressure and temperature conditions in the combustion chamber and the reactivity of the air-fuel mixture. In DF combustion by contrast, the start of combustion is triggered by the diesel injection as in conventional diesel engines.

A modern 21 PC diesel engine was converted to realise four different combustion processes: the original diesel operation, DF operation by the DDI concept, conventional DF operation by PFI of NG and monovalent spark ignited (SI) natural gas operation.

This paper is the culmination of a holistic investigation into the DDI concept carried out in a period of over 2 years, which was conducted both experimentally and numerically. In previous publications the most important application parameters of the DDI concept were covered, the operating strategy was explained and a comparison with the monovalent SI natural gas operation was given $[4,20]$. This publication focuses on hardware variations which were performed on the engine test bench.

An overview of the research on DF combustion is first provided and definitions are introduced. Following on from this in Sect. 4 the mechanisms of DF combustion are covered, the source of the high HC emissions with PFI and the effect of DDI are explained. In Sects. 5 and 6 the experimental setup and the methodology are reviewed. Sect. 7 presents the results of a variation of the compression ratio $\varepsilon$, an experimental study of different charge 


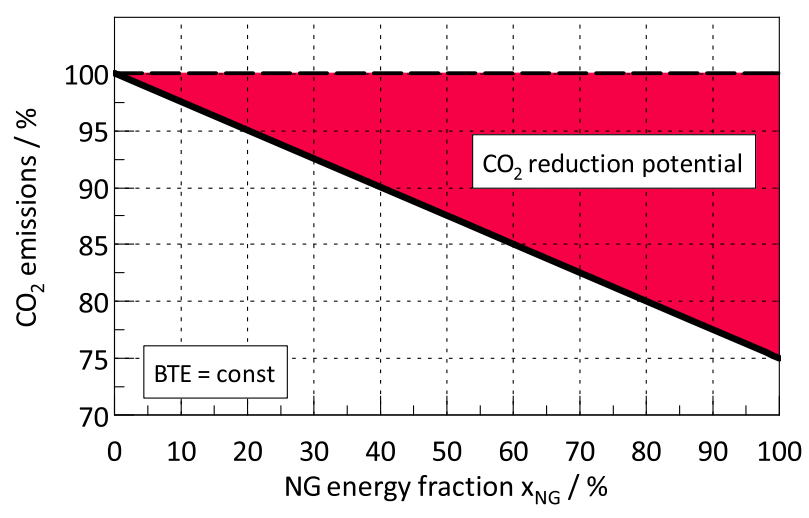

Fig. $2 \mathrm{CO}_{2}$ emissions in dependency of the NG energy fraction under the assumption of equal brake thermal efficiencies (BTEs) and complete combustion

motion pattern, a comparison with conventional diesel and gasoline engines as well as the results of exhaust gas aftertreatment with a three-way catalyst (TWC).

\section{State of the art}

Dual fuel combustion in general is not a novel approach. Although, various fuel combinations are viable, the most common and investigated combination is natural gas and diesel. Dual fuel engines are state of the art for large engines in marine applications and power generation [24]. A first OEM solution [25] and retrofit solutions [22] which both fulfil the EU 5 emission standard have been reported for heavy duty (HD) commercial vehicles. No series application has been reported in passenger cars as yet. An overview of concepts, research activities and applications across all engine sizes is given in [16].

The research of NG-diesel dual fuel combustion for PC and HD engines focuses mainly on two concepts. The most common approach is the port injection of NG and direct injection of diesel. This concept is also the easiest one to realise, as the NG supply can be retrofitted to a conventional diesel engine. The approach implies a homogeneous air-NG mixture in the combustion chamber which is compressed during the compression stroke. The mixture is ignited by a diesel pilot injection close to top dead centre (TDC). This concept was experimentally studied by Königsson [10], May et al. [11] and Garcia and Tunestal [6]. The challenge of this approach is to deal with high HC emissions in low load operation. The reason will be highlighted in Sect. 4. More fundamental experimental work was carried out by Schlatter in a rapid compression and expansion machine [19]. Also Tsuru, Takasaki et al. conducted fundamental experimental work with the focus on large engines [23].
The second concept, which is studied in the literature, features DI of both NG and diesel. This concept can be subdivided by the level of the NG injection pressure. According to the injection pressure different operating modes can be realised. Westport Innovations Inc. developed a twin-fuel injector [13] for high pressure direct injection of NG (HPDI) up to 600 bar. McTaggart-Cowan and Munshi et al. contributed significantly to this concept [12]. This injector has been developed for HD engines and features two separate needles in one case. HPDI provides a different operating mode compared to the PFI of NG. In this concept air is inducted and compressed in the combustion chamber. A diesel pilot quantity is then injected which self-ignites. After this NG is injected which burns in a non-premixed manner similar to the combustion in conventional diesel engines. The problem of high unburned $\mathrm{HC}$ emissions is circumvented with this concept. A series application for HD commercial vehicles is pending. The second subgroup of DI concepts utilises low pressure direct injection of NG. The injection pressure of these concepts is in the range of 16 bar. Experimental investigations of monofuel passenger car engines with natural gas DI and homogeneous charge have been carried out by Hofherr [8], Seboldt et al. [17] and Sevik et al. [18]. However, natural gas DI also offers the possibility to stratify the charge. The effects of NG stratification in monofuel PC engines have been studied experimentally by Friedrich et al. [5] and Melaika and Dahlander [14]. Baratta et al. [1] investigated the phenomena numerically by means of CFD simulations.

Investigations of dual fuel combustion with low pressure direct injection of NG and diesel (DDI-Dual Direct Injection) for a PC engine have been reported by the authors in [4]. Likewise to PFI an air-NG mixture is compressed in the combustion chamber and ignited by a diesel pilot injection. The direct injection of NG, however, offers an additional degree of freedom-the injection timing of NG. Thus, a stratification of the air-NG mixture becomes feasible and the problem of high $\mathrm{HC}$ emissions during low load operation can be mitigated as suggested in [11] and demonstrated in [4, 21]. Subsequently, this concept is further elaborated.

\section{Definitions}

The definitions used in this paper are introduced below. Equation (1) defines the air-NG equivalence ratio $\lambda_{\mathrm{NG}}$ which refers to the air-NG mixture only. This parameter characterises the stoichiometry of the mixture in which the diesel spray is injected and therefore influences the completeness of combustion. 

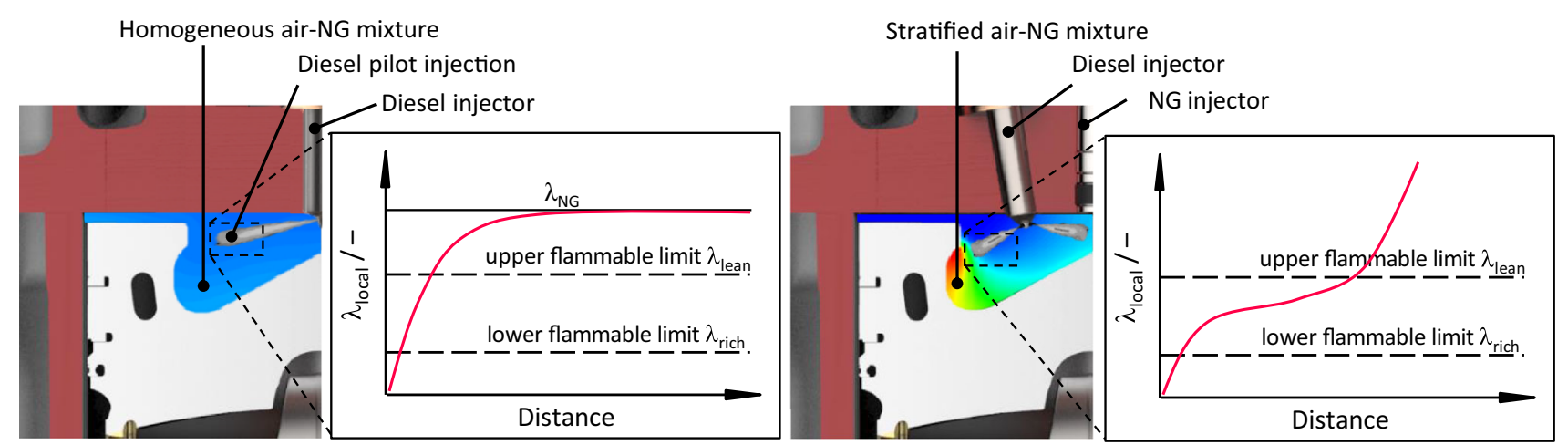

Fig. 3 Model representation of the mixture formation in DF combustion with PFI of NG (left) and DDI (right)

$$
\lambda_{\mathrm{NG}}=\frac{m_{\mathrm{air}}}{m_{\mathrm{NG}} \cdot L_{\mathrm{st}_{\mathrm{NG}}}}
$$

By contrast, the global equivalence ratio $\lambda_{\text {global }}$ defined in Eq. (2) considers both fuels and describes the overall stoichiometry.

$$
\lambda_{\text {global }}=\frac{m_{\mathrm{air}}}{m_{\mathrm{NG}} \cdot L_{\mathrm{st}_{\mathrm{NG}}}+m_{\text {Diesel }} \cdot L_{\mathrm{st}_{\text {Diesel }}}}
$$

Equation (3) indicates the NG energy fraction $x_{\mathrm{NG}}$. It describes the share of $\mathrm{NG}$ on the total fuel energy. High values are desired in order to gain maximum possible $\mathrm{CO}_{2}$ savings.

$$
x_{\mathrm{NG}}=\frac{m_{\mathrm{NG}} \cdot \mathrm{LHV}_{\mathrm{NG}}}{m_{\mathrm{NG}} \cdot \mathrm{LHV}_{\mathrm{NG}}+m_{\text {Diesel }} \cdot \mathrm{LHV}_{\text {Diesel }}}
$$

The unburned species $\Delta \zeta_{\text {IC }}$ are defined in Eq. (4). It is a measure to describe the losses due to incomplete combustion. $\Delta \zeta_{\text {IC }}$ is the ratio of the energy contained in the engine-out $\mathrm{HC}$ and carbon monoxide (CO) emissions and the total fuel energy.

$$
\Delta \zeta_{\mathrm{IC}}=\frac{m_{\mathrm{CO}} \cdot \mathrm{LHV}_{\mathrm{CO}}+m_{\mathrm{HC}} \cdot \mathrm{LHV}_{\mathrm{HC}}}{m_{\mathrm{NG}} \cdot \mathrm{LHV}_{\mathrm{NG}}+m_{\text {Diesel }} \cdot \mathrm{LHV}_{\text {Diesel }}}
$$

\section{Origin of the $\mathrm{HC}$ emissions}

The high HC emissions are a major obstacle for the series application of DF combustion processes in the PC sector. Their origin and the effect of charge stratification on the $\mathrm{HC}$ emissions are thus reviewed below. A more detailed investigation can be found in [21].

The HC emissions are closely linked to the local air-fuel equivalence ratio. Figure 3 on the left illustrates the model representation of the DF combustion with PFI of NG. It displays the mixture formation close to firing TDC. In the combustion chamber there is a homogeneous air-NG mixture, the stoichiometry of it equals $\lambda_{\mathrm{NG}}$. In this air-NG mixture diesel is injected to initiate the combustion. The diesel injection influences the local stoichiometry. There is a gradient from $\lambda_{\text {lo- }}$ cal $=0$ inside the liquid core of the diesel spray towards $\lambda_{\text {local }}=\lambda_{\mathrm{NG}}$ outside areas penetrated by the diesel spray. $\lambda_{\mathrm{NG}}$ must be within the lower $\left(\lambda_{\text {rich }} \approx 0.7\right.$ [2]) and upper flammable limit ( $\lambda_{\text {lean }} \approx 2$ [2]) of natural gas for a flame to propagate through the combustion chamber. Consequently, the completeness of combustion strongly depends on $\lambda_{\mathrm{NG}}$. An air-NG mixture above the upper flammable limit leads to flame extinguishing which results in high $\mathrm{HC}$ and $\mathrm{CO}$ emissions.

Figure 4 states experimental data of DF combustion with $\mathrm{NG} \mathrm{PFI}$ in the operating point $\mathrm{BMEP}=5 \mathrm{bar} /$

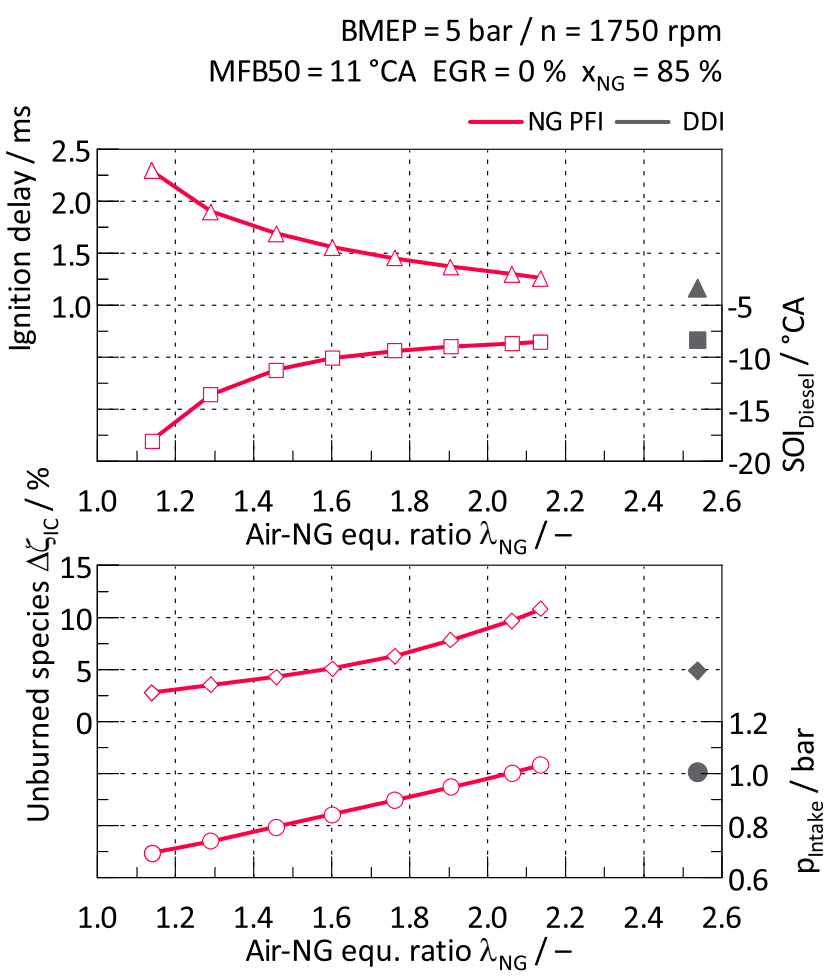

Fig. 4 Variation of $\lambda_{\mathrm{NG}}$ and the correlation with the ignition delay and the unburned species $\Delta \zeta_{\text {IC }}$ for PFI of NG and DDI 
$n=1750 \mathrm{rpm}$. It depicts a variation of $\lambda_{\mathrm{NG}}$ at constant MFB50 and the influence on the unburned species $\Delta \zeta_{\mathrm{IC}}$ and the ignition delay. The NG energy fraction $x_{\mathrm{NG}}$ is set to $85 \%$ which results in a diesel injection of $2.7 \mathrm{mg} /$ cycle. The diesel rail pressure is set to 400 bar and MFB50 is $11^{\circ}$ CA. The air-NG equivalence ratio $\lambda_{\mathrm{NG}}$ is varied by gradually closing the throttle valve. Starting at wide open throttle the intake manifold pressure $p_{\text {Intake }}$ is 1030 mbar high which results in $\lambda_{\mathrm{NG}}=2.14$. The stoichiometry of the air-NG mixture exceeds the upper flammable limit and as a result the unburned species $\Delta \zeta_{\mathrm{IC}}$ account for $10.8 \%$ of the total fuel energy. However, as the compression pressure is high the ignition conditions for the diesel pilot injection (DPI) are favourable and the ignition delay is small. By gradually closing the throttle valve $p_{\text {Intake }}$ is lowered and the air-NG equivalence ratio $\lambda_{\mathrm{NG}}$ reduces. The unburned species decrease considerably along with this process. However, the ignition delay rises due to the lower compression pressure. In order to maintain constant MFB50 the start of the diesel injection $\left(\mathrm{SOI}_{\text {Diesel }}\right)$ needs to be advanced. This means that pressure and temperature at SOI $_{\text {Diesel }}$ decrease further resulting in the strong increase of the ignition delay.

At an air-NG equivalence ratio $\lambda_{\mathrm{NG}}$ of 1.14 the intake manifold pressure of $p_{\text {Intake }}=700$ mbar cannot be reduced further while maintaining constant MFB50 due to the weak ignition of the diesel pilot injection. A further reduction was still favourable, however, for low unburned species. Figure 5 illustrates this intrinsic trade-off in low load operation by plotting the unburned species against the ignition delay. Conditions favourable for complete combustion of the air-NG mixture deteriorate the diesel ignition and vice versa. In addition, lower loads than $\mathrm{BMEP}=5$ bar require an even lower intake manifold pressure to keep $\lambda_{\mathrm{NG}}$ in a favourable range. Another approach to reduce $\lambda_{\mathrm{NG}}$ is exhaust gas recirculation (EGR) while keeping the throttle valve wide open, yet it entails the same correlations. Also the combination of EGR and throttled operation is not rewarding.

In the DDI concept the PFI of NG is replaced by low pressure direct injection to mitigate this trade-off. DI offers an additional degree of freedom, which is the injection timing of NG. This enables a stratification of the air-NG mixture. Figure 3 illustrates on the right side the model representation of the mixture formation of the DDI concept. The air-NG mixture is no longer homogeneous, as the $\mathrm{NG}$ is injected late in the compression stroke and caught in the piston bowl. The local equivalence ratio $\lambda_{\text {local }}$ ranges from air-only in the proximity of the squish area to ideally unity in the piston bowl. In the liquid core of the diesel spray $\lambda_{\text {local }}$ equals 0 . In Fig. 4 experimental data of the DDI concept is also displayed. It demonstrates that with charge stratification a significant reduction of the unburned species

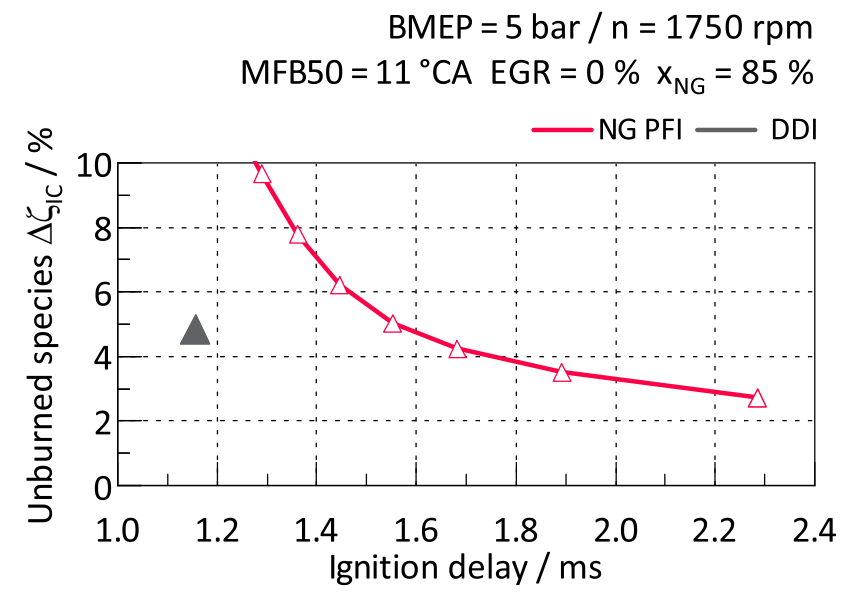

Fig. 5 Trade-off between complete combustion and favourable ignition conditions of the diesel spray in DF combustion with PFI of NG during low load operation. This trade-off is mitigated with the DDI concept

is achieved without the need to reduce the intake manifold pressure. A short ignition delay of the diesel spray is thus maintained. Figure 5 illustrates that with DDI the explained trade-off is mitigated.

\section{The DDI concept}

A state-of-the-art passenger car diesel engine compliant with EU 6 emission standards was adapted to realise NGdiesel DF combustion. The base diesel engine characteristics are stated in Table 1. As the investigated DF concept features direct injection of NG and diesel it is also referred to as dual direct injection (DDI) concept.

The layout of the DDI combustion system is depicted in Fig. 6. The NG injectors were placed in the centre of the combustion chamber taking the mechanical constraints into

Table 1 Engine characteristics and technology of the base diesel engine

\begin{tabular}{ll}
\hline Cylinder & 4 \\
Displacement volume & 2.01 \\
Bore/stroke & $84 \mathrm{~mm} / 90 \mathrm{~mm}$ \\
Compression ratio $\varepsilon$ & $16.5: 1$ \\
Number of valves & 4 \\
Rated power & $140 \mathrm{~kW} / 4000 \mathrm{rpm}$ \\
Rated torque & $400 \mathrm{Nm} / 1750 \mathrm{rpm}$ \\
Technology & Common-rail injection system (2000 bar) \\
& VNT turbocharger with intercooler \\
& Cooled and uncooled EGR \\
& Throttle valve \\
& Swirl flap \\
& EU 6 certification \\
\hline
\end{tabular}




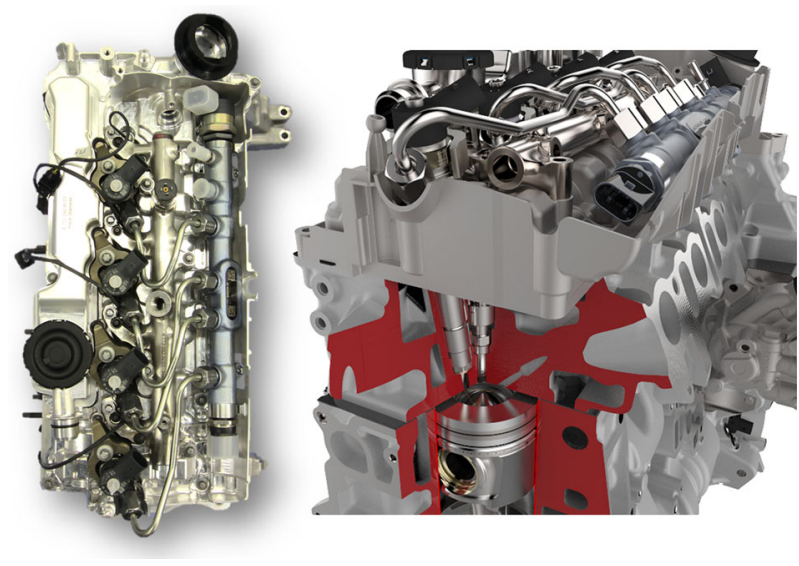

Fig. 6 The layout and mechanical realisation of the DDI concept

account. The diesel injectors were installed eccentrically and slightly tilted. One exhaust valve per cylinder had to be removed to accommodate both injectors within the limited space of the combustion chamber. The series diesel injectors with eight holes were replaced by injectors with six holes, an asymmetric spray pattern and reduced flow rate to account for the altered orientation and the pilot quantities injected. The NG injectors were supplied by Delphi and featured an outward-opening, tapered nozzle tip. The max. injection pressure was $16 \mathrm{bar}$, further information on the injector can be found in [9]. In order to realise these adaptions a specifically cast and machined cylinder head was essential. The actuation of the NG injectors was carried out by a separate control unit and a power amplifier. The diesel injectors and other actuators (e.g. EGR, VNT) were actuated by the series engine control unit.

The NG injection pressure of 16 bar was chosen, because the pressure level affects the cruising range of $\mathrm{CNG}$ vehicles. Common CNG tank systems provide a supply pressure of $200 \mathrm{bar}$. As soon as the supply pressure approaches the injection pressure the tank needs to be refilled. Therefore, a low injection pressure contributes to a higher vehicle cruising range. Yet it limits the maximum degree of stratification. The injection pressure constrains the latest possible injection timing of NG in a working cycle. A moderate charge stratification is achieved with 16 bar considering that a supercritical pressure ratio across the nozzle tip is required for stable NG injection.

\section{Methodology}

For the development of the DDI combustion process both experimental and simulative investigations were conducted. This section gives an overview of the development methodology used during the project. Based on the experimental results the combustion process was analysed

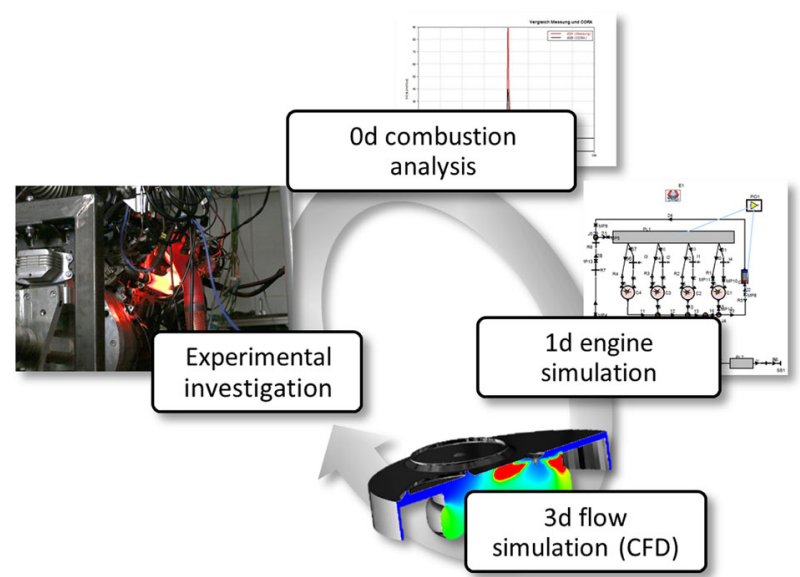

Fig. 7 The holistic development process followed during the project

and optimised with various simulations. The holistic development process is shown in Fig. 7.

\subsection{Measurements}

The investigations were carried out in five stationary load points as stated in Table 2. Three of these are representative for the NEDC (New European Driving Cycle) as depicted in Fig. 8. Additionally, one medium load and one full load operating point were selected. In the following the load points are used in abbreviated notations.

Furthermore, the pursued operating strategy for the DDI combustion process is demonstrated in Fig. 8. The operating modes are divided into:

- Idling until low load operation: diesel only mode.

- Low until medium load operation: stratified air-NG mixture with $\lambda_{\text {global }}>1$

- Medium until full load operation: homogeneous airNG mixture with $\lambda_{\text {global }}=1$

A detailed explanation and information how the operating strategy was derived can be found in [20]. Only results of the load points 3/1500 and 11/2000 are discussed in this publication. At the beginning of this project the influence of the main application parameters was investigated:

Table 2 Examined load points and short form of notation

\begin{tabular}{lll}
\hline BMEP (bar) & $n(\mathrm{rpm})$ & Short form \\
\hline 3 & 1500 & $3 / 1500$ \\
5 & 1750 & $5 / 1750$ \\
11 & 2000 & $11 / 2000$ \\
15 & 1750 & $15 / 1750$ \\
Max. & 2000 & Max./2000 \\
\hline
\end{tabular}




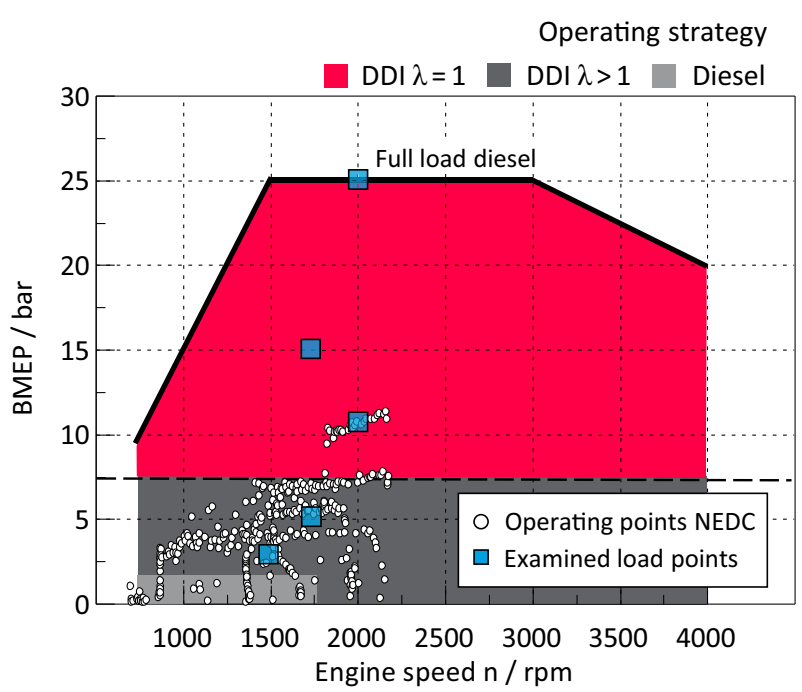

Fig. 8 Examined load points and the DDI operating strategy

- Start of NG injection ( $\mathrm{SOI}_{\mathrm{NG}}$ )

- NG energy fraction $x_{\mathrm{NG}}$

- EGR and EGR temperature

- Air-NG equivalence ratio $\lambda_{\mathrm{NG}}$

- MFB50

- Swirl flap position

- Diesel rail pressure

- NG rail pressure

- Diesel injection pattern (one vs. two pilot injections)

Based on these results the DDI combustion process was optimised in each load point. Due to the large number of parameters, the optimisation was carried out by using design of experiments (DoE). Depending on the operating mode, different criteria for the optimisation result. In stratified operation, the DDI combustion process was optimised on minimum unburned species and maximum brake thermal efficiency while maintaining the same low nitrogen oxide $\left(\mathrm{NO}_{x}\right)$ emissions as the base diesel engine. The combustion process in stoichiometric mode was optimised for minimum unburned species and
Table 3 The investigated hardware parameters

\begin{tabular}{lll}
\hline Intake port design & Swirl (base) & Tumble \\
Piston bowl shape & $\omega$, flat & $\omega$, flat, lens \\
Compression ratio $\varepsilon$ & $14.5,16.5$ & 16.5 \\
NG injection & DI, PFI & DI \\
Ignition & DPI, SI & DPI \\
\hline
\end{tabular}

maximum brake thermal efficiency regardless of the $\mathrm{NO}_{x}$ emissions, because a three-way catalyst can be used for the exhaust gas aftertreatment. More information on the influence of the main application parameters can be obtained in [4].

In addition to the application parameters the influence of various hardware parameters on the dual fuel combustion process was also investigated. The performed variations are stated in Table 3. The effect of different charge motion patterns (swirl, tumble and squish) on the combustion process was investigated. This was achieved by different piston bowl shapes (Fig. 9) and intake port designs (Fig. 10). The idea was to generate a wide range of different charge motion patterns in order to depict the effects on the combustion process as drastically as possible.

Due to the complex flow situation in the combustion chamber the layout of the intake ports and the piston geometries was supported by $3 \mathrm{~d}$ CFD simulations. Two intake port designs in combination with three different piston shapes were investigated. For these investigations, two custom-built cylinder heads were manufactured. Moreover, the influence of the compression ratio $\varepsilon$ and the advantages and disadvantages of NG direct injection in comparison to NG port fuel injection were analysed. Even different ignition concepts (diesel pilot injection (DPI) vs. spark ignition (SI)) and combustion processes were realised on the same base engine [20].

The experimental investigations were concluded with the analysis of exhaust gas aftertreatment. The focus was on the conversion of the unburned HC emissions,
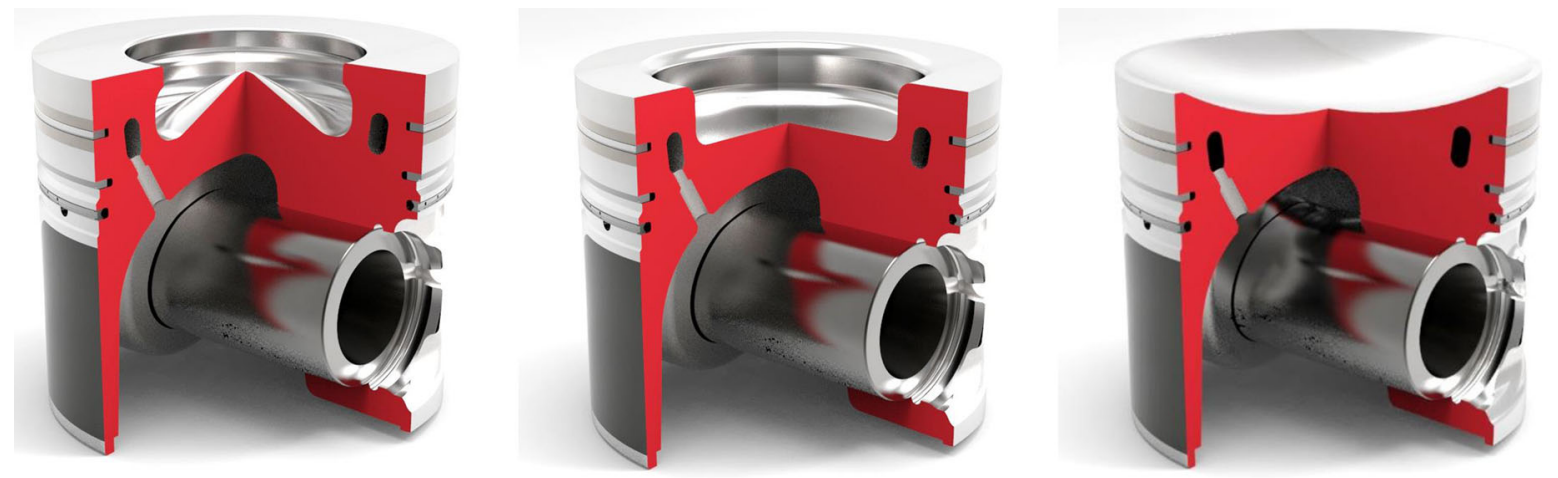

Fig. 9 Investigated piston geometries with $\varepsilon=16.5$ (from left to right): $\omega$-bowl (base), flat-bowl and lens-bowl 


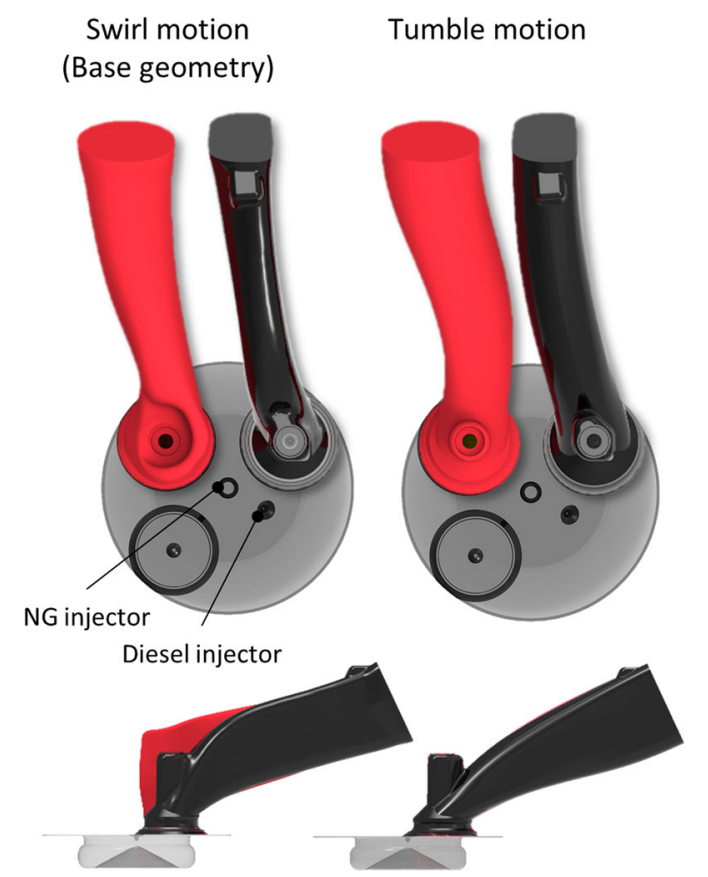

Fig. 10 Intake port design: base geometry with swirl motion (left) and geometry with tumble motion (right)

particularly on methane. For these experiments a specially designed bypass system was integrated on the engine test bench. Thereby, the measurements of various catalysts could be conducted under identical testing conditions.

The focus of this paper is on the experimental investigations of the hardware variations and the exhaust gas aftertreatment.

\subsection{Simulations}

The experimental investigations were supported by various simulations. In addition to the $0 \mathrm{~d}$ combustion analysis, $1 \mathrm{~d}$ engine simulations of the DDI concept were performed. Based on these results, the necessary boundary conditions for the $3 \mathrm{~d}$ CFD simulation were determined. The CFD simulation process is shown in Fig. 11. The aim of the simulations was to achieve a better understanding of the charge motion, the mixture formation of natural gas and diesel as well as the dual fuel combustion.

\section{Results}

In this section, the results are presented with a focus on performing hardware variations. All variations were conducted on the same base engine to ensure best possible comparability of the results. Throughout the measurement campaign NG with a methane content higher than 95 vol.\% was used.

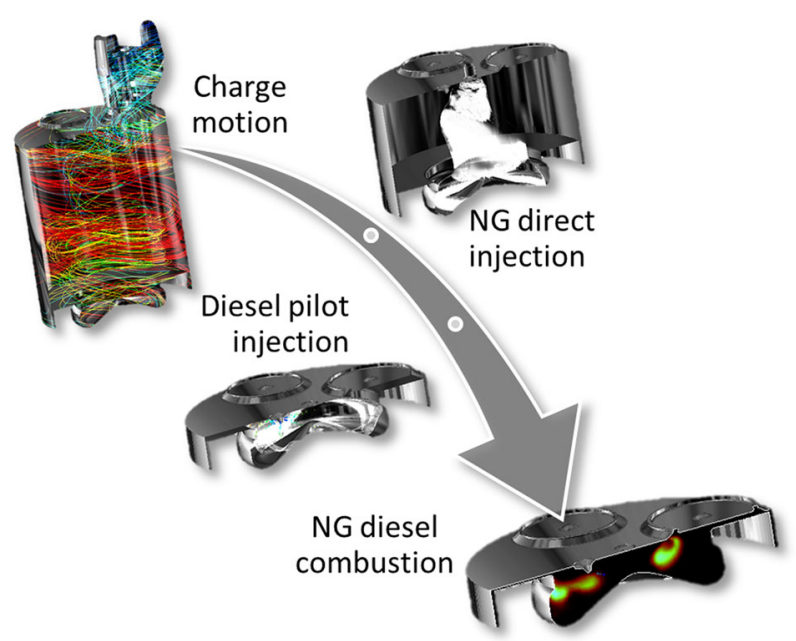

Fig. 11 The CFD simulation process

\subsection{Comparison of port fuel injection (PFI) of NG and dual direct injection (DDI)}

Similar results have been published earlier by the authors in [16]. However, to understand the concept, the advantages and disadvantages of DDI, a comparison with PFI is stated for two load points. Both combustion concepts were realised on the same base engine with differently machined cylinder heads. The geometry of the combustion chamber, the port design, the piston geometry and the compression ratio were identical.

The results stated represent the optimum which is achieved with each concept. This means while the hardware parameters $(\varepsilon$, piston geometry, port design, etc.) are identical, the application parameters (injection timing, boost pressure, swirl flap position, EGR, etc.) are different and optimised for each combustion process. Only the NG energy fraction $x_{\mathrm{NG}}$ is identical. The values of all application parameters are stated in Table 4 in the Appendix. The criterion for optimisation is minimum unburned species $\Delta \zeta_{\text {IC }}$ and maximum brake thermal efficiency. Additionally, in lean operation the engine-out $\mathrm{NO}_{x}$ emissions must be on the same low level as the $\mathrm{NO}_{x}$ emissions of the base diesel engine.

Figure 12 presents the results of the load point $3 /$ 1500. According to the operating strategy presented in Fig. 8 the DDI engine is operated in stratified mode. Accordingly, $\mathrm{SOI}_{\mathrm{NG}}$ is set to $70{ }^{\circ} \mathrm{CA}$. In both cases $x_{\mathrm{NG}}=80 \%$ and high amounts of EGR are used (for further details see Tab. 4). The benefit of DDI is clearly evident as the unburned species $\Delta \zeta_{\text {IC }}$ are reduced by twothirds and the indicated efficiency is increased by $6 \%$ Pt. The reduction of $\Delta \zeta_{\text {IC }}$ results from a concentration of the NG in the piston bowl. The local air-fuel equivalence ratio inside the bowl is shifted from the upper flammable 


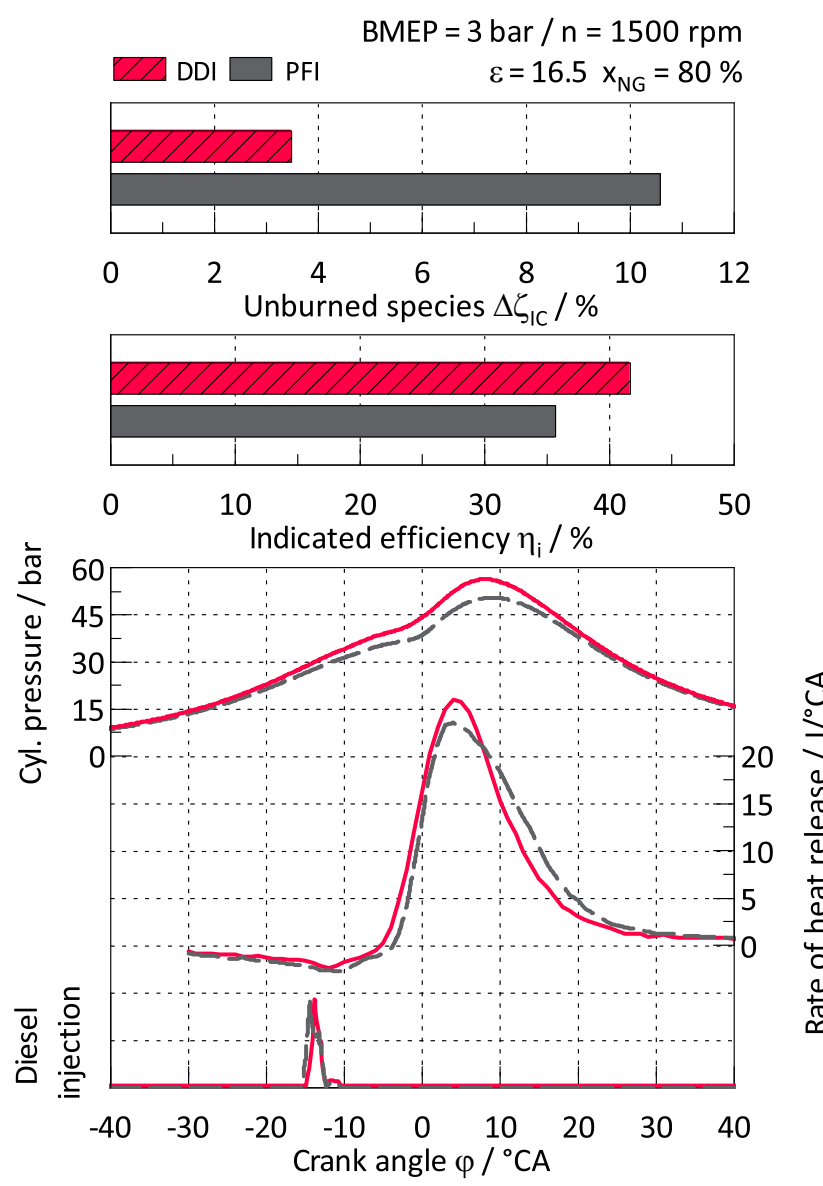

Fig. 12 Comparison of dual fuel combustion with natural gas PFI and DDI in the load point $3 / 1500$

limit towards stoichiometry. This promotes a complete combustion. However, the increase in indicated efficiency is not explained by a reduction of unburned species only. Different gas properties of the cylinder charge also improve the efficiency. In the DDI case, a higher dilution of the charge can be realised ( $\lambda_{\text {global }}$ and the amount of EGR are higher, see Table 4 for more information) and the NG is injected later in the compression stroke. These factors influence the indicated efficiency positively as well.

The situation is different in the load point 11/2000. According to the operating strategy stated in Fig. 8 the DDI engine is operated homogeneously and stoichiometrically in this load point. The NG injection is set to $\mathrm{SOI}_{\mathrm{NG}}=300{ }^{\circ} \mathrm{CA}$. Also the PFI concept is operated stoichiometrically. The air-fuel mixing is better with PFI as the NG is introduced already before the intake valves and there is more time for mixing. In addition, in the PFI concept, the diesel injector is located centrally and features an 8-hole nozzle, which is advantageous in comparison to the eccentric installation and the 6-hole nozzle of the DDI concept. These differences are observed in the

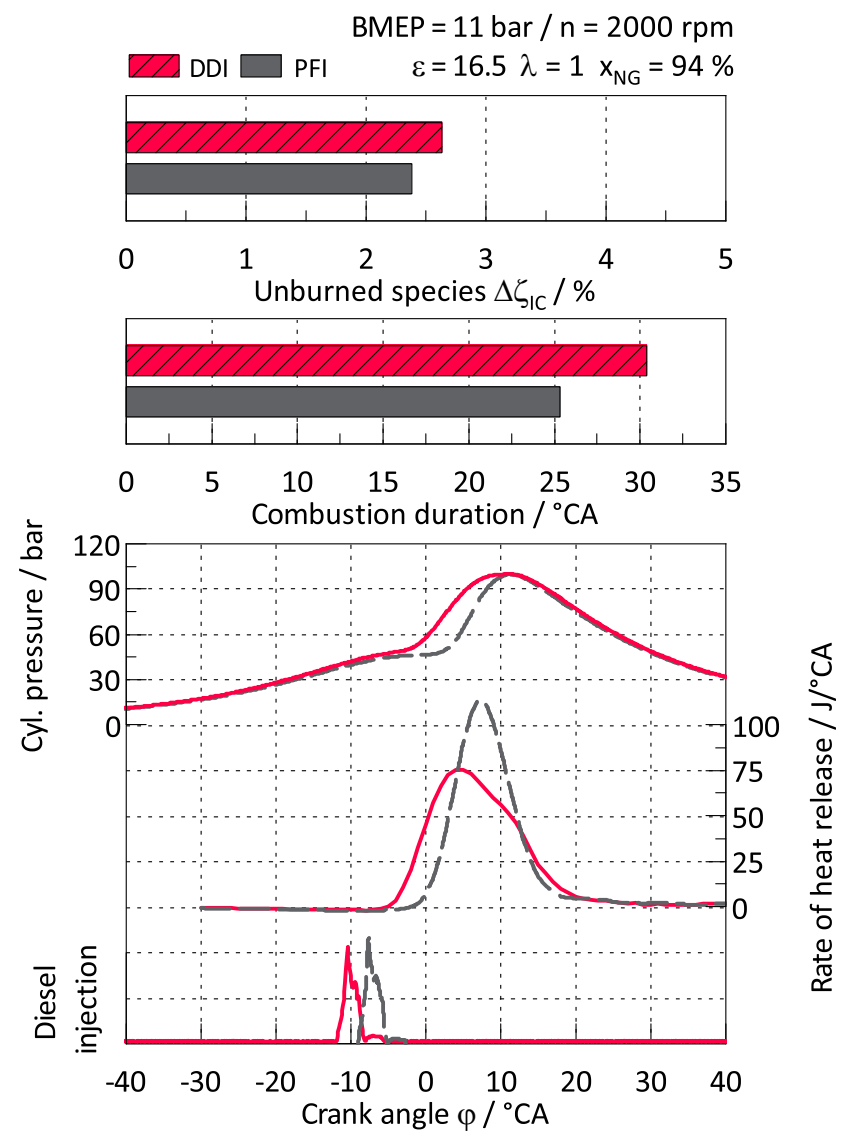

Fig. 13 Comparison of dual fuel combustion with natural gas PFI and DDI in the load point $11 / 2000$

measurement data depicted in Fig. 13. PFI provides slightly lower unburned species and the combustion is significantly faster as the combustion duration and the rate of heat release (ROHR) indicate.

\subsection{Study on effects of charge motion and piston geometry}

The aim of the investigations is to analyse the influence of different charge motion patterns on the DDI combustion process. Basically, the charge motion can be divided into swirl, tumble and squish. The charge motion influences the turbulence in the combustion chamber significantly. As already shown in Figs. 9 and 10 two different intake port geometries and three piston shapes were designed. Figure 14 shows the investigated combinations of intake port geometries and piston shapes and the resulting charge motion patterns.

In addition to the turbulence, the charge motion influences the mixture formation. There is a trade-off due to the different operating strategies. An increase in turbulence improves the homogenisation of the air-fuel mixture in the combustion chamber. This is desirable in stoichiometric 
operation to achieve complete combustion. In the stratified operation a better homogenisation leads to a deterioration of the stratified mixture. As a result, the unburned $\mathrm{HC}$ emissions increase.

Figure 15 shows the results in the load point $3 / 1500$ during lean and stratified operation. The direct injection of $\mathrm{NG}$ is started late in the compression stroke $\left(-70{ }^{\circ} \mathrm{CA}<\mathrm{SOI}_{\mathrm{NG}}<-60^{\circ} \mathrm{CA}\right)$.

The $\mathrm{NO}_{x}$ emissions are at the same low level for all variants. The NG energy fraction $x_{\mathrm{NG}}$ is $80 \%$ for all tests (for more details on application parameters see Table 5).

It is clearly evident that the unburned species $\Delta \zeta_{\mathrm{IC}}$ of the two configurations with a distinct piston bowl (flat-bowl and $\omega$-bowl) are significantly lower than those of the configuration with the lens-bowl. Due to the late direct injection of NG into the combustion chamber the distinct piston bowl traps the injected natural gas. Whereas the open geometry of the lens-bowl distributes the introduced natural gas in the entire combustion chamber. As a result, no stratification is achieved. Besides an increase of the unburned species $\Delta \zeta_{\mathrm{IC}}$ this leads to a longer combustion duration and to a deterioration of the combustion stability characterised by the coefficient of variation COVIMEP. Due to the low load point it is difficult to quantify the impact of the different charge motion patterns. Nevertheless, the configuration tumble intake ports and flat-bowl piston has an advantage in the indicated efficiency in this load point.

In the load point 11/2000 which was optimised for stoichiometric operation, the impact of different charge motions on the DDI combustion process is more visible. All variants combine the same NG energy fraction rate $x_{\mathrm{NG}}$ of $96 \%$ and the same $\mathrm{SOI}_{\mathrm{NG}}$ of $360{ }^{\circ} \mathrm{CA}$. Moreover, EGR was not used in this load point. The remaining application parameters are stated in Table 6. Figure 16 shows both experimental and simulation results. The turbulence level in the combustion chamber which is primarily influenced by the charge motion, can be quantified with the turbulent kinetic energy (TKE). The results of the cold flow CFD simulation show that the tumble flow generates a higher absolute turbulence. However, the TKE of the tumble variants decrease faster towards TDC. The turbulence level of the combination tumble intake port design and lens-bowl piston is the least after TDC. Correlations can be determined by comparing these findings from the simulation with the experimental data. As can be seen from the ROHR the increased turbulence due to the tumble flow leads to a steeper rise at the beginning. The combination of tumble ports with lens-bowl piston in particular brings advantages during the first third of the combustion. By contrast, the heat release of the swirl flow is the slowest during this period. These findings can be derived from the simulation reviewing the TKE - a higher turbulence level for the

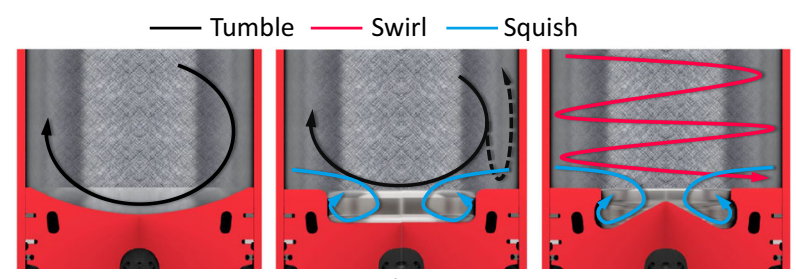

Tumble / Lens-bowl
Swirl / $\omega$-bowl

Fig. 14 Investigated charge motion patterns (intake port design/ piston bowl shape)

tumble flow leads to fast combustion at the beginning. The relation is reversed, however, at the end of the combustion. Due to the long-lasting turbulence of the swirl flow, the combustion is faster in the last third compared to the tumble configurations. As a result, the end of the combustion for the swirl and $\omega$-bowl combination is achieved earlier. A good compromise is the combination of tumble flow with a flat-bowl piston. The interaction between tumble and squish flow shows good results in both simulation and experiment.

In addition to the combustion, the turbulence also has a major impact on the mixture formation. The higher turbulence and the open piston shape of the lens-bowl result in improved mixing of the directly injected NG in the combustion chamber. As a result, the unburned $\mathrm{HC}$ emissions decreases. The variants with a deep piston bowl ( $\omega$ and flatbowl) have a negative influence on the mixture preparation. The unburned species $\Delta \zeta_{\text {IC }}$ of the $\omega$ and flat-bowl are thus higher than those of the lens-bowl. Moreover, the better homogenisation with the lens-bowl has a positive effect on the combustion stability COVIMEP in comparison to the other configurations. Due to the faster combustion at the beginning and the better mixture formation the tumble/ lens-bowl combination has advantages in terms of the indicated efficiency. The base configuration (swirl $/ \omega$-bowl) cannot compensate the disadvantages of the inferior homogenisation by means of faster burning towards the end of the combustion process. To conclude, different requirements for the charge motion exist. Combining all the desired properties in one configuration is not a realistic possibility. Primarily, a piston bowl is needed to maintain a stratified charge during low load operation. The lensshaped piston affects this circumstance negatively. However, the combination of tumble and lens-bowl improves the mixture homogenisation during stoichiometric operation. A good compromise is the configuration tumble port design with a flat-bowl piston.

\subsection{Variation of the compression ratio and knocking}

The combustion of the air-NG mixture is dominated by the regime of a premixed combustion. The risk of knocking is 


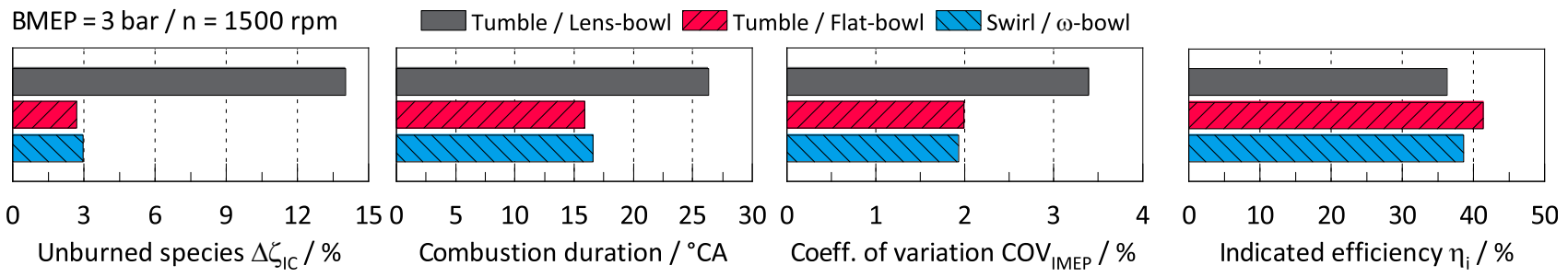

Fig. 15 Comparison of different charge motion patterns in the load point 3/1500

$\mathrm{BMEP}=11 \mathrm{bar} / \mathrm{n}=2000 \mathrm{rpm}$

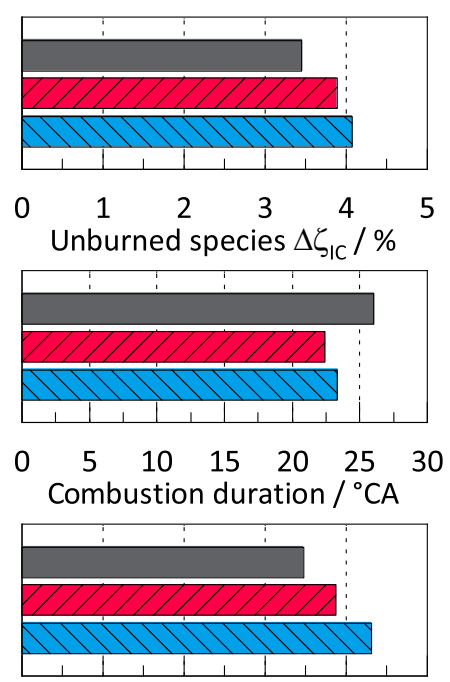

$\begin{array}{llllll}0 & 0.2 & 0.4 & 0.6 & 0.8 & 1.0\end{array}$

Coeff. of variation $\operatorname{COV}_{\text {IMEP }} / \%$

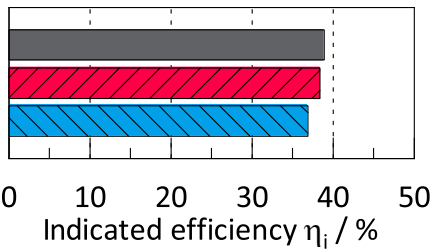

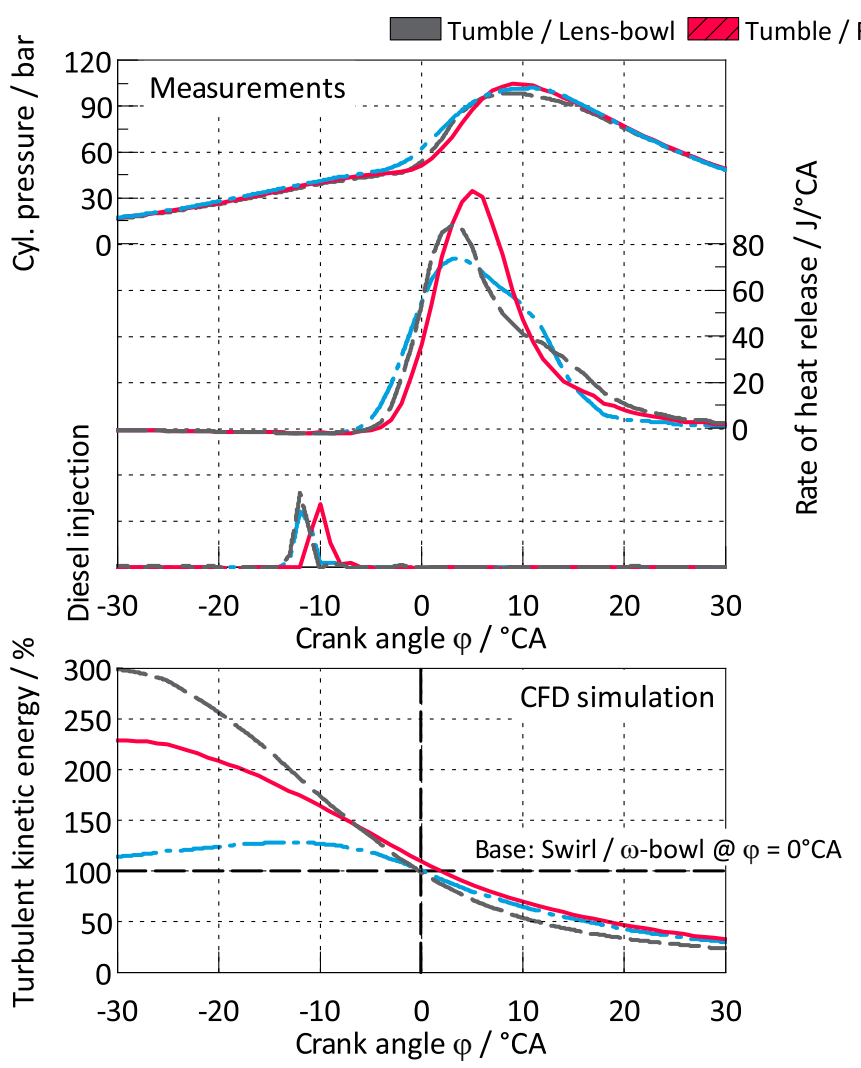
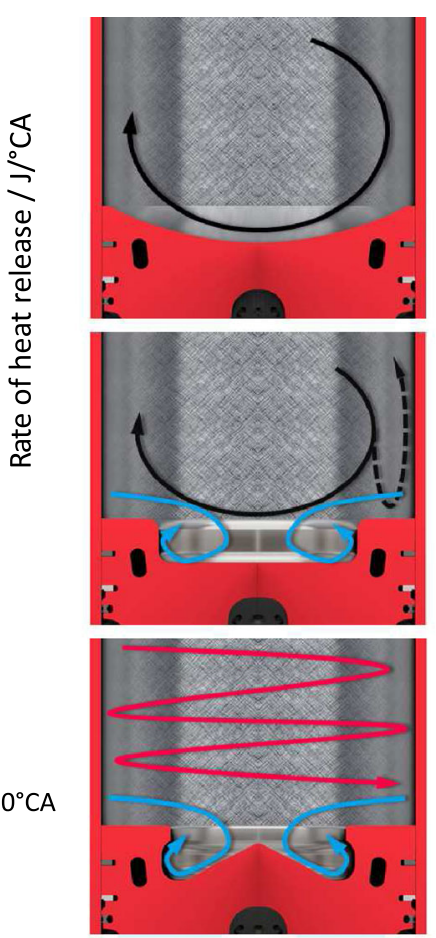

Fig. 16 Comparison of different charge motion patterns in the load point 11/2000

thus also present. This is particularly the case if the compression ratio $\varepsilon$ is high as it is in the case of the presented DDI concept $(\varepsilon=16.5)$. However, the variation of $\varepsilon$ was performed to determine the limitations of the combustion process and not due to excessive knocking at high loads. With $\varepsilon=16.5$ at $n=2000 \mathrm{rpm}$ and $\mathrm{MFB50}=14{ }^{\circ} \mathrm{CA}$ the onset of knocking is detected at BMEP $=23$ bar.

This maximum load is achieved, however, with the PFI concept, which features a four valve cylinder head. Knocking starts earlier with the DDI concept which only has one exhaust valve. It is assumed that at high loads the single exhaust valve becomes hotter and more residual gas is potentially trapped in the cylinder. Both effects cause earlier knocking. The maximum load of the investigated DDI engine is thus not representative for the combustion process. Furthermore, it must be pointed out that knocking is highly dependent on the fuel used. NG with a methane content higher than 95 vol.\% was used throughout the measurement campaign. During the investigation of the knock limit the methane content was 98.4 vol.\%.

Subsequently, a comparison is given of measurement data with $\varepsilon=16.5$ and 14.5 for two load points. The reduction of the compression ratio was achieved by a reduced conrod length of $1 \mathrm{~mm}$ and an increase of the bowl volume. The general $\omega$-shape of the bowl was maintained and the compression height of the piston also remained unchanged. Again, the displayed measurement results represent the optimum in terms of efficiency and unburned species, which is achieved with each setup. Furthermore, the engine-out $\mathrm{NO}_{x}$ emissions match the low level of the 


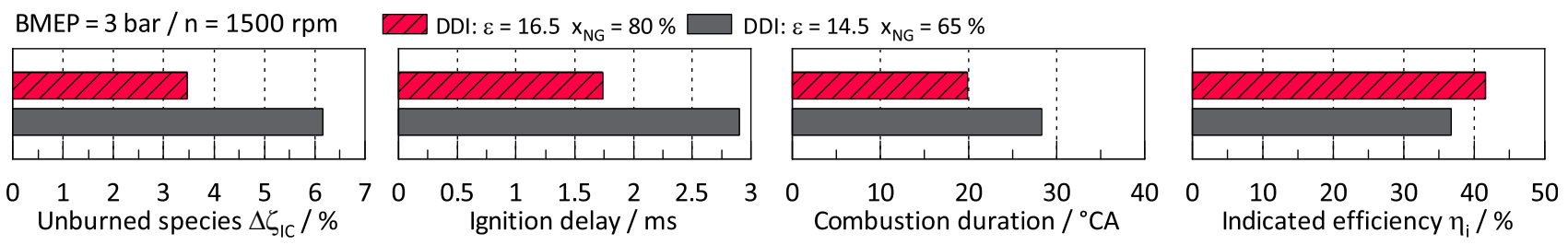

Fig. 17 Comparison of measurements with compression ratio $\varepsilon=14.5$ and $\varepsilon=16.5$ in the load point $3 / 1500$

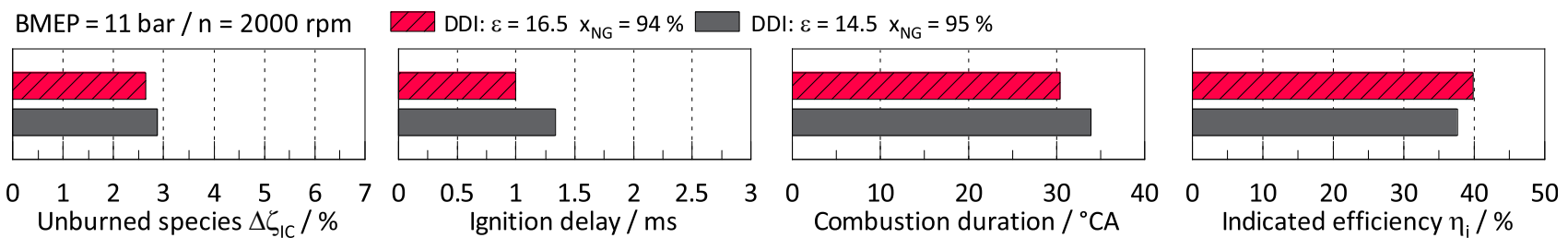

Fig. 18 Comparison of measurements with compression ratio $\varepsilon=14.5$ and $\varepsilon=16.5$ in the load point $11 / 2000$

base diesel engine in lean and stratified operation. The associated application parameters of the depicted measurement data are stated in Table 7. Figure 17 displays results of the load point $3 / 1500$. The variant with $\varepsilon=14.5$ has an inferior performance in all aspects. The reduced compression leads to a reduced compression pressure and temperature, which negatively affects the ignition conditions of the diesel pilot spray. The injection quantity must be raised and the injection timing needs to be advanced to compensate for the inferior ignition conditions. The higher diesel quantity is reflected in the low NG energy fraction $x_{\mathrm{NG}}$ of only $65 \%$. Advancing the diesel injection results in the large increase of the ignition delay as the ignition conditions become even worse. Furthermore, due to the lower pressure and temperature at TDC the whole combustion evolves at lower pressure and temperature levels which in total negatively affects the combustion speed. The lower NG energy fraction $x_{\mathrm{NG}}$ leads to a very lean air-NG mixture of $\lambda_{\mathrm{NG}}=2.44$ resulting in a strong increase of the unburned species, even though the charge is stratified. Finally, a reduction of $\varepsilon$ also reduces the thermodynamic efficiency of the engine. According to Carnot, the efficiency reduces if the heat release evolves at lower temperature levels [15]. All these aspects mentioned cumulate in a penalty in indicated efficiency of almost $5 \% P t$..

Figure 18 depicts the load point 11/2000. The trends are the same, but the effects are softened compared to the results at $\mathrm{BMEP}=3$ bar in Fig. 17. The reason is that although the DDI engine is operated stoichiometrically at $\mathrm{BMEP}=11$ bar and lean at BMEP $=3 \mathrm{bar}$, the in-cylinder mass increases by $20 \%$ resp. $30 \%$ due to the higher load. Along with the higher mass the intake manifold pressure increases by 200 mbar resp. 280 mbar. Thus, the compression pressure and the temperature at TDC are higher and the effects described above are mitigated. The penalty in indicated efficiency due to the lower compression ratio reduces to $2 \% \mathrm{Pt}$.

To conclude, the variation of the compression ratio points out that a high compression ratio similar to conventional diesel engines is vital for the presented DDI concept. At low load operation in particular it is important to ensure good ignition conditions for the diesel pilot spray. Naturally, the high $\varepsilon$ facilitates knocking, therefore, it is crucial to use NG with a high methane share.

\subsection{Comparison of the DDI concept with conventional combustion processes}

Finally, the results of the DDI concept are compared to a conventional diesel and gasoline engine in two load points. The diesel engine, which also served as base engine for the realisation of the DDI concept and a state-of-the-art gasoline engine were chosen for this comparison. The gasoline engine is also a turbocharged 4-cylinder engine with 21 capacity. It features gasoline direct injection (GDI), a variable valve train and a compression ratio of $\varepsilon=10$. For this comparison the standard configuration of the DDI concept is chosen. It consists of the piston with $\omega$-bowl, a compression ratio of 16.5 and the swirl design of the intake ports.

The measurement results of the DDI concept represent the optimum achieved in terms of unburned species $\Delta \zeta_{\text {IC }}$ and brake thermal efficiency. The associated application parameters are stated in Table 4 in the column DDI.

Figure 19 presents the comparison in the load point 3/1500. Despite the low load, the DDI engine reaches 
Fig. 19 Comparison of the DDI concept with conventional combustion processes in the load point $3 / 1500$

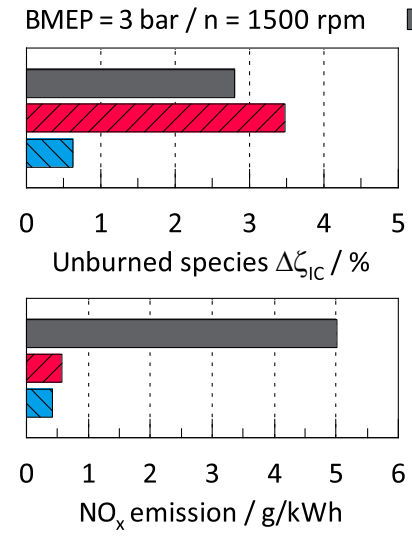

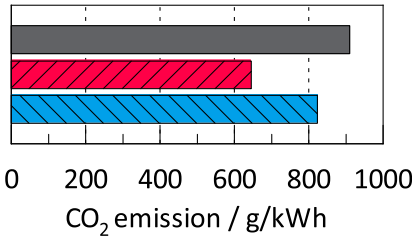

Indicated efficiency $\eta_{\mathrm{i}} / \%$

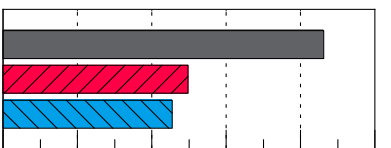

$\begin{array}{lllllll}0 & 100 & 200 & 300 & 400 & 500 & 0\end{array}$

Exhaust gas temperature $/{ }^{\circ} \mathrm{C}$

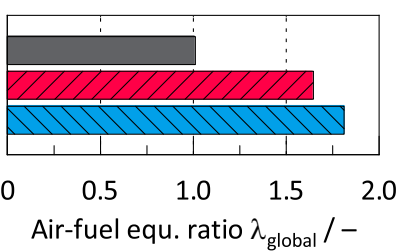

almost the same level of unburned species as the gasoline engine. The diesel engine exhausts almost no unburned species due to the non-premixed combustion. The indicated efficiency of the DDI engine is higher than the efficiency of the conventional diesel engine in this load point despite the higher unburned species. The reason is a faster and earlier combustion as confirmed by the indicating data in Fig. 20.

The NG energy fraction $x_{\mathrm{NG}}$ is $79 \%$ in this load point. Under the condition of equal brake thermal efficiencies the feasible $\mathrm{CO}_{2}$ reduction amounts to $20 \%$. An even greater $\mathrm{CO}_{2}$ reduction is achieved, however, as the brake thermal efficiency of the DDI concept is higher compared to the gasoline and diesel engines. Compared to the diesel engine the $\mathrm{CO}_{2}$ emissions are reduced by $22 \%$ and compared to the gasoline engine even by $29 \%$. The $\mathrm{CO}_{2}$ emissions are calculated from the injected fuel masses assuming complete conversion.

The $\mathrm{NO}_{x}$ emissions of the DDI engine are kept on the same low level as the diesel engine, because both engines feature lean exhaust gas in this operating point. Thus, the feasibility of $\mathrm{NO}_{x}$ aftertreatment with existing and proven technology should be ensured. The $\mathrm{NO}_{x}$ emissions of the gasoline engine are one magnitude higher due to the stoichiometric operation. The reduction of $\mathrm{NO}_{x}$ is realised by a three-way catalyst in case of the gasoline engine.

A large difference is also observed in the exhaust gas temperatures (EGT). The gasoline engine reaches an EGT of $430{ }^{\circ} \mathrm{C}$ due to the stoichiometric operation and the comparably low compression ratio. The DDI concept reaches only $250{ }^{\circ} \mathrm{C}$ in this load point. The low temperature makes the aftertreatment of the unburned species very challenging as the $\mathrm{HC}$ emissions consist mainly of $\mathrm{CH}_{4}$ which is a particularly stable molecule. High temperatures are required for the oxidation of $\mathrm{CH}_{4}$ in a catalyst. The problem of $\mathrm{CH}_{4}$ oxidation is further elaborated in Sect. 7.5.
Figure 20 displays the corresponding indicating data of the three engine concepts. The lower compression ratio of the gasoline engine is clearly visible by comparing the cylinder pressure traces. The ROHR of the gasoline and the DDI engine are almost symmetric. The ROHR of the diesel engine features the typical asymmetric shape with two peaks, corresponding to the pilot injection and the main injection. This is an indication that the dual fuel combustion is dominated by the regime of a premixed combustion regime.

Figure 21 displays the results in the load point $11 /$ 2000. Again, the data of the DDI combustion process represents the optimised operation and the associated application parameters are stated in Table 4 . In-line with the operating strategy published in Fig. 8 the DDI engine is operated stoichiometrically. The NG energy fraction $x_{\mathrm{NG}}$ is $94 \%$ in this load point. The unburned species of the DDI

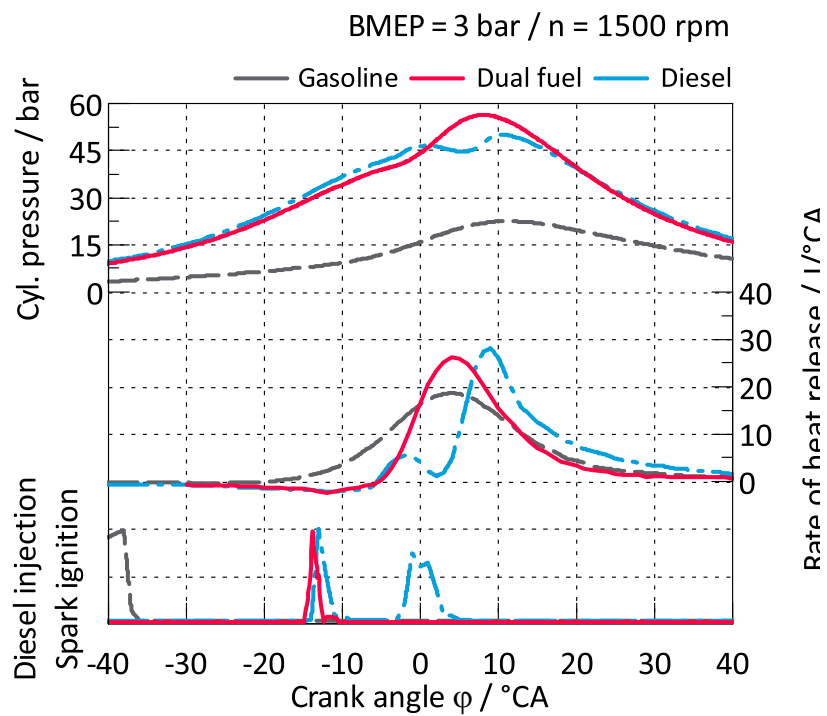

Fig. 20 Associated indicating data of the three combustion processes in the load point $3 / 1500$ 
Fig. 21 Comparison of the DDI concept with conventional combustion processes in the load point $11 / 2000$
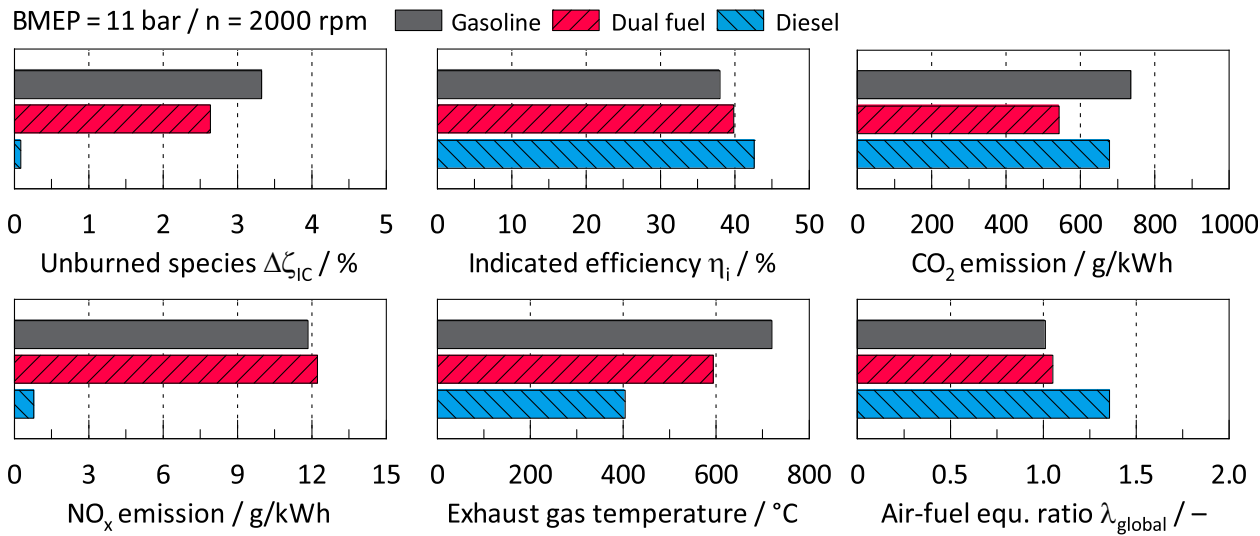

engine are below the level of the gasoline engine. This demonstrates that at high loads the DDI combustion performs well. In accordance with this, the indicated efficiency of the DDI engine is higher by $2 \%$ Pt.. The higher efficiency is a result of the higher compression ratio, lower unburned species and a faster combustion. However, the diesel engine outperforms the DDI engine by another $2 \%$ Pt in indicated efficiency. The surplus results from almost complete combustion, lower wall heat losses and beneficial gas properties due to the lean combustion.

Under the condition of equal brake thermal efficiencies a $\mathrm{CO}_{2}$ reduction of $24 \%$ can be achieved for the given NG energy fraction $x_{\mathrm{NG}}$ of $94 \%$. Considering the difference in the efficiencies the $\mathrm{CO}_{2}$ emissions are reduced by $26 \%$ compared to the gasoline engine and by $20 \%$ compared to the diesel engine.

The level of the $\mathrm{NO}_{x}$ emissions is comparable to the gasoline engine as the DDI engine is also operated stoichiometrically. The EGT of the DDI engine is $200{ }^{\circ} \mathrm{C}$ higher compared to the diesel engine, however, it is still $120{ }^{\circ} \mathrm{C}$ below the gasoline engine. This offset results mainly from different compression ratios. Nevertheless, it is still sufficient to ensure oxidation of the $\mathrm{CH}_{4}$ emissions in a catalyst.

Figure 22 depicts the associated indicating data. The fast combustion of the gasoline and the DF combustion is clearly recognisable. During the compression stroke the cylinder pressure of the diesel engine is higher compared to the DDI engine, because the in-cylinder mass is higher resulting from lean operation.

To conclude, the comparison demonstrates that with the DDI concept $\mathrm{CO}_{2}$ reductions of $20 \%$ are feasible over vast areas of the operating map in comparison to diesel and gasoline engines. Furthermore, the DDI concept outperforms the efficiency of the gasoline engine and at low loads even the efficiency of the diesel engine. However, the comparison also reveals that low load operation is critical for the DDI concept as the exhaust gas temperature is very low and the exhaust gas is lean. This is challenging for the exhaust gas aftertreatment of the unburned species as elaborated in the following section.

\subsection{Exhaust gas aftertreatment}

Experimental investigations on the exhaust gas aftertreatment were carried out to achieve a holistic assessment of the DDI combustion process. In view of the different operating modes various requirements arise for the exhaust gas aftertreatment system. A PGM-based three-way catalyst (Pt:Rh 5:1, $30 \mathrm{~g} / \mathrm{ft} 3$ ) was used for the base investigations. Due to the high NG energy fraction $x_{\mathrm{NG}}$ during DF operation the $\mathrm{HC}$ emissions mainly consist of methane. As a result of the chemical stability of $\mathrm{CH}_{4}$ a high activation energy is required for the catalytic oxidation. Thus, the investigations were focused on the $\mathrm{CH}_{4}$ conversion.

Figure 23 presents the results in the load point 11/2000. The influence of the air-fuel equivalence ratio $\lambda_{\text {global }}$ on the

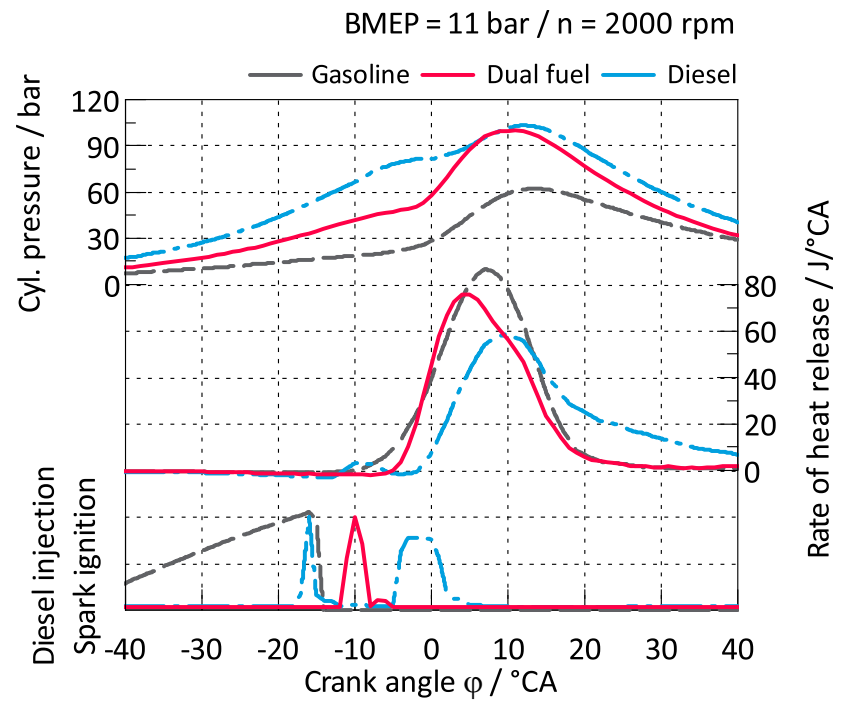

Fig. 22 Associated indicating data of the three combustion processes in the load point $11 / 2000$ 
$\mathrm{CH}_{4}$ conversion was investigated. In addition to the $\mathrm{CH}_{4}$ conversion rate the temperatures before and in the catalyst are depicted. Particularly striking is the strong influence of the air-fuel equivalence ratio $\lambda_{\text {global }}$ on the $\mathrm{CH}_{4}$ conversion. In the optimal $\lambda$ operating window $\left(0.98<\lambda_{\text {global }}<0.99\right)$ $\mathrm{CH}_{4}$ conversion rates higher than $98 \%$ are achieved. However, the $\mathrm{CH}_{4}$ conversion in lean operation $\left(\lambda_{\text {global }}>1\right)$ decreases drastically. For example, at an air-fuel equivalence ratio of $\lambda_{\text {global }}=1.1$ the $\mathrm{CH}_{4}$ conversion is less than $10 \%$. The inlet temperature of the catalyst fluctuates between 500 and $550{ }^{\circ} \mathrm{C}$ depending on $\lambda_{\text {global }}$. In the optimum operating range of the catalyst the temperature in the catalyst rises to $640{ }^{\circ} \mathrm{C}$.

A comparison with the results in Fig. 19 reveals exhaust gas temperatures of $250{ }^{\circ} \mathrm{C}$ in the load point $3 / 1500$ and an air-fuel equivalence ratio of $\lambda_{\text {global }}=1.65$. Under these conditions no $\mathrm{CH}_{4}$ conversion can be achieved. Even with catalyst heating strategies it is not possible to achieve acceptable $\mathrm{CH}_{4}$ conversion rates. This is evident, because the measured light-off temperature for optimal air-fuel equivalence ratios $\left(0.98<\lambda_{\text {global }}<0.99\right)$ is approx. $450{ }^{\circ} \mathrm{C}$.

In addition to the gaseous pollutant emissions particulate emissions were also assessed. Figure 24 depicts the particle count for the DDI concept compared to the base diesel engine. Due to the very low diesel quantity the particle count of the DF combustion is significantly lower. In the load point 3/1500 the particle emission of the DDI engine is lower than those of the diesel engine by four orders of magnitude. Even during stoichiometric operation in the load point $11 / 2000$, when $\lambda_{\text {global }}$ is below the diesel soot

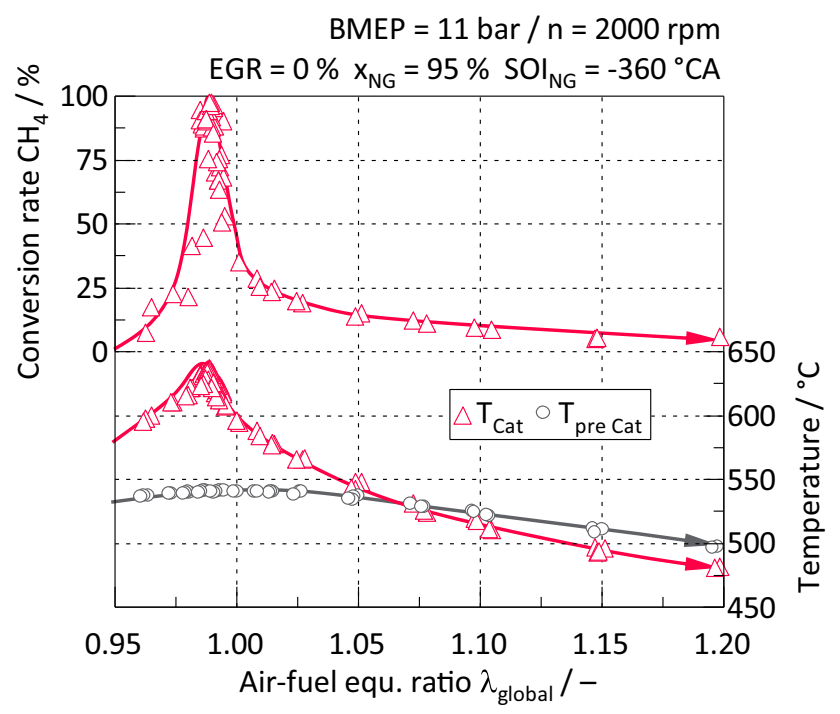

Fig. 23 Conversion rate of $\mathrm{CH}_{4}$ and temperatures before and in the catalyst in the load point $11 / 2000$

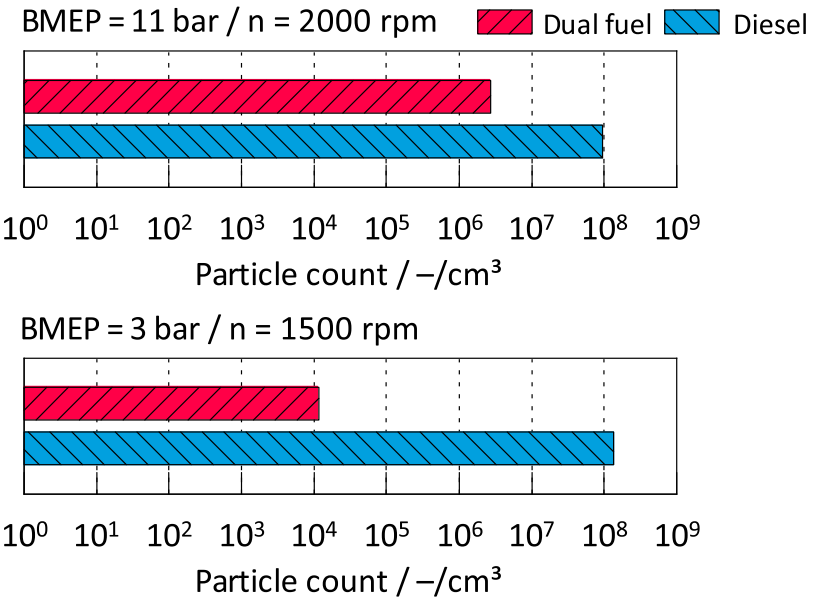

Fig. 24 Particle count for DF and diesel in the load points 3/1500 and $11 / 2000$

limit, the particle emission of the DDI concept is two orders of magnitude lower than that of the diesel engine.

\section{Summary}

This work gives an overview of the holistic investigation of a natural gas-diesel dual fuel combustion process for passenger car applications. The motivation for this work is the $\mathrm{CO}_{2}$ savings potential of natural gas. The major challenge of natural gas-diesel dual fuel combustion processes is the high emission of unburned HC during low load operation. The DDI concept features natural gas direct injection and thus offers an additional degree of freedom, the injection timing of natural gas. A late injection of natural gas during the compression stroke leads to a stratified air-NG mixture in the combustion chamber and to a reduction of the local air-fuel equivalence ratio. This results in a remarkable reduction of the unburned $\mathrm{HC}$ emissions compared to concepts with port fuel injection of natural gas. $\mathrm{CO}_{2}$ savings of $20 \%$ compared to the diesel engine and more than $25 \%$ compared to the gasoline engine are demonstrated. However, the exhaust gas aftertreatment remains critical for passenger car applications as the remaining unburned $\mathrm{HC}$ emissions consist mainly of methane. High exhaust gas temperatures are needed due to the high activation energy required for the oxidation of methane. The lean and stratified operation and the high compression ratio influence the necessary temperatures negatively. As a consequence, the focus of further investigations needs to be on the reduction of both the engine-out and tailpipe methane emissions. 
Acknowledgements Open access funding provided by Graz University of Technology. The authors would like to thank Delphi for the supply of the CNG DI injectors. This project has received funding from the Austrian Research Promotion Agency (FFG).

Open Access This article is distributed under the terms of the Creative Commons Attribution 4.0 International License (http://creative commons.org/licenses/by/4.0/), which permits unrestricted use, distribution, and reproduction in any medium, provided you give appropriate credit to the original author(s) and the source, provide a link to the Creative Commons license, and indicate if changes were made.

\section{Appendix}

Here the associated application parameters are stated of the published measurement data.

Table 4 Application parameters of the comparison of PFI and DDI

\begin{tabular}{|c|c|c|c|c|}
\hline \multirow{2}{*}{$\begin{array}{l}\text { Configuration } \\
\text { Load point }\end{array}$} & \multicolumn{2}{|l|}{ PFI } & \multicolumn{2}{|l|}{ DDI } \\
\hline & $3 / 1500$ & $11 / 2000$ & $3 / 1500$ & $11 / 2000$ \\
\hline$x_{\mathrm{NG}}(\%)$ & 79 & 92 & 79 & 94 \\
\hline$\lambda_{\text {global }}(-)$ & 1.55 & 1.05 & 1.64 & 1.05 \\
\hline$\lambda_{\mathrm{NG}}(-)$ & 1.99 & 1.12 & 1.92 & 1.06 \\
\hline $\mathrm{SOI}_{\mathrm{NG}}\left({ }^{\circ} \mathrm{CA}\right)$ & -360 & -360 & -70 & -300 \\
\hline $\mathrm{SOI}_{\text {Diesel }}\left({ }^{\circ} \mathrm{CA}\right)$ & -15.2 & -8.8 & -14.7 & -11.7 \\
\hline$p_{\text {Rail }}$ diesel(bar) & 400 & 400 & 800 & 400 \\
\hline$p_{\text {Rail }} \mathrm{NG(bar)}$ & 8 & 8 & 16 & 16 \\
\hline $\mathrm{MFB} 50\left({ }^{\circ} \mathrm{CA}\right)$ & 6.1 & 8.0 & 6.5 & 7.0 \\
\hline $\begin{array}{l}\text { Swirl flap }(\%) \\
0 \% \text {...fully open }\end{array}$ & 55 & 0 & 55 & 0 \\
\hline $\operatorname{EGR}(\%)$ & 39 & 0 & 43 & 0 \\
\hline $\begin{array}{l}\text { EGR cooler } \\
\text { Bypass }\end{array}$ & Yes & - & Yes & - \\
\hline
\end{tabular}

Table 5 Associated application parameters of the investigation of different charge motions in the load point $3 / 1500$

\begin{tabular}{llll}
\hline $\begin{array}{l}\text { Intake port } \\
\text { Piston }\end{array}$ & $\begin{array}{l}\text { Tumble } \\
\text { Lens-bowl }\end{array}$ & $\begin{array}{l}\text { Tumble } \\
\text { Flat-bowl }\end{array}$ & $\begin{array}{l}\text { Swirl } \\
\omega \text {-bowl }\end{array}$ \\
\hline$x_{\mathrm{NG}}(\%)$ & 79 & 79 & 79 \\
$\lambda_{\text {global }}(-)$ & 1.56 & 1.72 & 1.62 \\
$\lambda_{\mathrm{NG}}(-)$ & 1.97 & 2.20 & 2.06 \\
$\mathrm{SOI}_{\mathrm{NG}}\left({ }^{\circ} \mathrm{CA}\right)$ & -70 & -70 & -60 \\
$\mathrm{SOI}_{\text {Diesel }}\left({ }^{\circ} \mathrm{CA}\right)$ & -13.4 & -16.8 & -17.2 \\
$p_{\text {Rail }}$ diesel(bar $)$ & 800 & 800 & 800 \\
$p_{\text {Rail }} \mathrm{NG}($ bar $)$ & 16 & 16 & 16 \\
MFB50 $\left({ }^{\circ} \mathrm{CA}\right)$ & 8.9 & 5.4 & 7.8 \\
Swirl flap $(\%)$ & 55 & 40 & 60 \\
$\quad 0 \%$...fully open & & & \\
EGR $(\%)$ & 40 & 42 & 43 \\
EGR cooler & Yes & yes & Yes \\
Bypass & & & \\
\hline
\end{tabular}

Table 6 Associated application parameters of the investigation of different charge motions in the load point $11 / 2000$

\begin{tabular}{llll}
\hline $\begin{array}{l}\text { Intake port } \\
\text { Piston }\end{array}$ & $\begin{array}{l}\text { Tumble } \\
\text { Lens-bowl }\end{array}$ & $\begin{array}{l}\text { Tumble } \\
\text { Flat-bowl }\end{array}$ & $\begin{array}{l}\text { Swirl } \\
\omega \text {-bowl }\end{array}$ \\
\hline$x_{\mathrm{NG}}(\%)$ & 96 & 96 & 96 \\
$\lambda_{\text {global }}(-)$ & 1.01 & 1.01 & 1.01 \\
$\lambda_{\mathrm{NG}}(-)$ & 1.05 & 1.05 & 1.05 \\
$\mathrm{SOI}_{\mathrm{NG}}\left({ }^{\circ} \mathrm{CA}\right)$ & -360 & -360 & -360 \\
$\mathrm{SOI}_{\text {Diesel }}\left({ }^{\circ} \mathrm{CA}\right)$ & -13.1 & -11.6 & -13.0 \\
$p_{\text {Rail }}$ Diesel(bar $)$ & 400 & 400 & 400 \\
$p_{\text {Rail }} \mathrm{NG}(\mathrm{bar})$ & 16 & 16 & 16 \\
$\mathrm{MFB50}\left({ }^{\circ} \mathrm{CA}\right)$ & 6.0 & 6.0 & 6.0 \\
Swirl flap $(\%)$ & 0 & 0 & 0 \\
$\quad 0 \%$...fully open & & & \\
EGR $(\%)$ & 0 & 0 & - \\
EGR cooler & - & - & \\
Bypass & & & \\
\hline
\end{tabular}

Table 7 Associated application parameters of the investigation of different compression ratios

\begin{tabular}{|c|c|c|c|c|}
\hline \multirow{2}{*}{$\begin{array}{l}\text { Compression ratio } \\
\text { Load point }\end{array}$} & \multicolumn{2}{|c|}{$\varepsilon=16.5$} & \multicolumn{2}{|c|}{$\varepsilon=14.5$} \\
\hline & $3 / 1500$ & $11 / 2000$ & $3 / 1500$ & $11 / 2000$ \\
\hline$x_{\mathrm{NG}}(\%)$ & 79 & 94 & 64 & 94 \\
\hline$\lambda_{\text {global }}(-)$ & 1.64 & 1.05 & 1.60 & 1.06 \\
\hline$\lambda_{\mathrm{NG}}(-)$ & 1.92 & 1.06 & 2.44 & 1.11 \\
\hline $\mathrm{SOI}_{\mathrm{NG}}\left({ }^{\circ} \mathrm{CA}\right)$ & -70 & -300 & -100 & -300 \\
\hline $\mathrm{SOI}_{\text {Diesel }}\left({ }^{\circ} \mathrm{CA}\right)$ & -14.7 & -11.7 & -21.8 & -10.7 \\
\hline$p_{\text {Rail }}$ Diesel(bar) & 800 & 400 & 400 & 400 \\
\hline$p_{\text {Rail }} \mathrm{NG(bar)}$ & 16 & 16 & 16 & 16 \\
\hline $\mathrm{MFB} 50\left({ }^{\circ} \mathrm{CA}\right)$ & 6.5 & 7.0 & 11.2 & 12.0 \\
\hline $\begin{array}{l}\text { Swirl flap }(\%) \\
0 \% \text {...fully open }\end{array}$ & 50 & 0 & 40 & 30 \\
\hline $\operatorname{EGR}(\%)$ & 43 & 0 & 40 & 0 \\
\hline $\begin{array}{l}\text { EGR cooler } \\
\text { Bypass }\end{array}$ & Yes & - & Yes & - \\
\hline
\end{tabular}

\section{References}

1. Baratta, M., Rapetto, N., Spessa, E., Fuerhapter, A., Philipp, H.: Numerical and experimental analysis of mixture formation and performance in a direct injection CNG engine. SAE Technical Paper, 2012-01-0401 (2012)

2. van Basshuysen, R.: Erdgas und erneuerbares Methan für den Fahrzeugantrieb. Springer, Berlin (2015)

3. European Parliament.: Regulation (EC) No 443/2009 of the European Parliament and of the Council of 23 April 2009 setting emission performance standards for new passenger cars as part of the Community's integrated approach to reduce $\mathrm{CO}_{2}$ emissions from light-duty vehicles. EU Regulation 443/2009 (2009) 
4. Fasching, P., Sprenger, F., Eichlseder, H.: Experimental optimization of a small bore natural gas-diesel dual fuel engine with direct fuel injection. SAE Int. J. Engines 9(2), 1072-1086 (2016)

5. Friedrich, W., Grzeszik, R., Wensing, M.: Mixture formation in a CNG-DI engine in stratified operation. SAE Technical Paper, 2015-24-2474 (2015)

6. Garcia, P., Tunestal, P.: Experimental investigation on CNGdiesel combustion modes under highly diluted conditions on a light duty diesel engine with focus on injection strategy. SAE Int. J. Engines 8(5), 2177-2187 (2015)

7. Heywood, J.B.: Internal Combustion Engine Fundamentals. McGraw-Hill, New York (1988)

8. Hofherr, T.: Potenzialbetrachtung effizienzsteigender Maßnahmen sowie Abgasnachbehandlungsmöglichkeiten eines direkteinblasenden Erdgasmotors für die PKW-Anwendung. Ph.D. thesis, TU Wien (2015)

9. Husted, H.L., Karl, G., Schilling, S., Weber, C.: Direct injection of CNG for driving performance with low $\mathrm{CO}_{2}$. In: 23rd Aachen Colloquium Automobile and Engine Technology, pp. 829-850. Aachen (2014)

10. Königsson, F.: On combustion in the CNG-diesel dual fuel engine. Ph.D. thesis, KTH Stockholm (2014)

11. May, I., Pedrozo, V., Zhao, H., Cairns, A., Wong, H., Bennicke, P.: Characterization and potential of premixed dual-fuel combustion in a heavy duty natural gas/diesel engine. SAE Technical Paper, 2016-01-0790 (2016)

12. McTaggart-Cowan, G.P., Jones, H.L., Rogak, S.N., Bushe, W.K., Hill, P.G., Munshi, S.R.: The effects of high-pressure injection on a compression-ignition, direct injection of natural gas engine. ASME J. Eng. Gas Turbines Power 129(2), 579-588 (2007)

13. McTaggart-Cowan, G., Mann, K., Huang, J., Singh, A., Patychuk, B., Zheng, Z.K., Munshi, S.: Direct injection of natural gas at up to 600 bar in a pilot-ignited heavy-duty engine. SAE Int. J. Engines 8(3), 981-996 (2015)

14. Melaika, M., Dahlander, P.: Experimental investigation of methane direct injection with stratified charge combustion in optical SI single cylinder engine. SAE Technical Paper, 2016-010797 (2016)

15. Pischinger, R., Klell, M., Sams, T.: Thermodynamik der Verbrennungskraftmaschine. Springer, New York (2009)
16. Redtenbacher, C., Kiesling, C., Wimmer, A., Sprenger, F., Fasching, P., Eichlseder, H.: Dual fuel combustion-a promising concept for small to large engines? In: 37th International Vienna Motor Symposium, pp. 403-428. Vienna (2016)

17. Seboldt, D., Lejsek, D., Wentsch, M., Chiodi, M., Bargende, M.: Numerical and experimental studies on mixture formation with an outward-opening nozzle in a SI engine with CNG-DI. SAE Technical Paper, 2016-01-0801 (2016)

18. Sevik, J., Pamminger, M., Wallner, T., Scarcelli, R., Reese, R., Iqbal, A., Boyer, B., Wooldridge, S., Hall, C., Miers, S.: Performance, efficiency and emissions assessment of natural gas direct injection compared to gasoline and natural gas port-fuel injection in an automotive engine. SAE Int. J. Engines 9(2), 1130-1142 (2016)

19. Schlatter, S.: Experimental and numerical characterization of enhanced ignition systems for large bore gas engines. Ph.D. thesis, ETH Zurich (2015)

20. Sprenger, F., Fasching, P., Eichlseder, H.: Erdgas-diesel dualdirect-injection-Ein alternatives Brennverfahren zur signifikanten $\mathrm{CO}_{2}$-Reduzierung. In:10. Tagung Diesel- und Benzindirekteinspritzung, pp. 441-467. Berlin (2016)

21. Sprenger, F., Fasching, P., Kammerstätter, S.: Experimentelle Untersuchung von Erdgas-Diesel Brennverfahren mit äußerer und innerer Gemischbildung für Pkw-Anwendungen. In:15. TagungDer Arbeitsprozess des Verbrennungsmotors, Graz (2015)

22. Stålhammar, P., Erlandsson, L., Willner, K., Johannesson, S.: Demonstration och utvärdering av dual-fuel-tekniken. Svenskt Gastekniskt Center AB, Report 233, isrn: SGC-R-233-SE (2011)

23. Tsuru, D., Kikunaga, S., Koga, T., Takasaki, K., Pirker, G., Wimmer, A.: Application of large-sized RCEM to a study on combustion in dual fuel gas engine operation. In: 4th Rostock Large Engine Symposium, pp. 294-305. Rostock (2016)

24. Troberg, M., Portin, K., Jarvi, A.: Update on Wärtsilä 4-stroke gas product development. Paper No. 406. In: CIMAC Congress 2013. Shanghai (2013)

25. Volvo Trucks.: Volvo Trucks first to market gas-powered truck for long-haul operations. Press release 31.5.2011 